Florida International University FIU Digital Commons

4-12-1995

\title{
Perceptions of collaboration between emergency nurses and paramedics
}

Linda Stacey Boylan

Florida International University

DOI: $10.25148 /$ etd.FI14051816

Follow this and additional works at: https://digitalcommons.fiu.edu/etd

Part of the Nursing Commons

\section{Recommended Citation}

Boylan, Linda Stacey, "Perceptions of collaboration between emergency nurses and paramedics" (1995). FIU Electronic Theses and Dissertations. 1778.

https://digitalcommons.fiu.edu/etd/1778

This work is brought to you for free and open access by the University Graduate School at FIU Digital Commons. It has been accepted for inclusion in FIU Electronic Theses and Dissertations by an authorized administrator of FIU Digital Commons. For more information, please contact dcc@fiu.edu. 
FLORIDA INTERNATIONAL UNIVERSITY

Miami, Florida

PERCEPTIONS OF COLLABORATION

BETWEEN

EMERGENCY NURSES AND PARAMEDICS

A thesis submitted in partial satisfaction of the requirements for the degree of

MASTER OF SCIENCE

IN

NURS ING

by

Linda stacey Boylan 
To: Acting Dean Jacqulin Hartley School of Nursing

This thesis, wxitten by Linda stacey Boylan, and entitied Collaboration between Emergency Room Nurses and Paramedics, having been approved in respect to style and intellectual content, is referred to you for judgement.

We have read this thesis and recommend that it be approved.

Deirdre Krause

Lowell Krokoff

Donna Safian-Rush, Major Professor

Date of Defense: Apri1 12, 1995

The thesis of Linda stacey Boylan is approved.

Acting Dean Jaoquin Hartley

School of Nursing

Dr. Richard L. Campbell

Dean of Graduate studies

Florida International University, 1995

ii 
DEDICATTON

I dedicate this thesis to my husband, Edwin Marshall Starks. Without his support, understanding, friendship and most of all his love, the completion of this work would not have been possible. I also dedicate this thesis to myself, for fulfiling an aspiration that contributes to my professional and personal growth. 
I wish to thank and recognize Dr. Donna Rush, Comittee Chairperson, as well as Committee Members, Dr. Deirdre Krause and Dr. Lowel1 Krokoff, for their ongoing guidance, assistance and expertise. I also wish to thark the Metro Dade County Fire Rescue and the community Hospitals for participating in the study A special acknowledgement of thanks to Mr. Bill Johnson, for his time and statistical. knowledge, in analyzing the data.

I would also like to thank my friends, colleen Bowers and carol Quairoli, for their assistance, encouragement, support and "downtime" which helped me keep the project in prospective and make it a reality. 
ABSTRACT OF THE THESIS

PERCEPTION OF COLLABORATION BETWEEN

EMERGENCY ROOM NURSES AND PARAMEDHCS

by

Linda stacey Boylan

Florida International university, 1994

Miami, Florida

Professor Donna Rush, Major Professor

Collaboration between emergency room (ER) nurses and paramedics is vital due to the increasing number of critically ill patients entering the hospital via the "911" system. This descriptive study examined the perception of the collaborative relationship using the Revised Pehl Collaboration scale (RPCS) and by qualitative data from four free response questions.

The results of this study indicated that the overall relationship between the ER nurses and paramedics was friendly but not fully trusting. The content analysis of the free response questions identified that the "report" of patient information was the origin the most conflict. The nurses felt that paramedic patient assessment, patient priorities, and by-pass protocol were problems. Whereas, 
the paramedics identified the nurses condescending manner and mistrust, not being "listened" to, and overcrowded emergency rooms as the source of conflict. Data was not statistically significant with regards to personal attributes or social denographics from the RPCS. 
Chapter

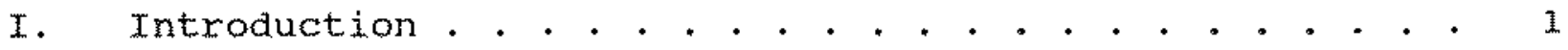

Problem Area . . . . . . . . . . . . . . . . . 1

Problem Statement. . . . . . . . . . . . . . . 5

Puxpose . . . . . . . . . . . . . . . . . . . . 7

Research Question . . . . . . . . . . . . . . . 8

study Varíables. . . . . . . . . . . . . . . . . . 9

Assumptions . . . . . . . . . . . . . . . . 10

Definition of terms . . . . . . . . . . . . . . 10

Significance . . . . . . . . . . . . . . . . 13

Nursing Implications . . . . . . . . . . . . . . 15

II. Review of the Literature. . . . . . . . . . . . . . 17

Introduction . . . . . . . . . . . . . . 17

Competition and collaboration . . . . . . . . . 17

Collaboration between Physicians and Nurses . . . 19

Nurse-Physician Conflict . . . . . . . . . . . 21

Collaboration between Nurses and other Health

Professionals . . . . . . . . . . . 23

Nurse-Paramedics Interaction . . . . . . . 24

Theoretical Framework . . . . . . . . . 27

King" Conceptual Framework for Nursing . . . . 27 
Comminication/Perception Theory....... . . 30

Collaborative Framework . . . . . . . . . . . 31

III. Methodology . . . . . . . . . . . . . . . . . 34

Design . . . . . . . . . . . . . . 34

sample . . . . . . . . . . . . . . . 34

Informed consent . . . . . . . . . . 36

Instrument . . . . . . . . . . . . 37

Procedure . ... . . . . . . . . . . 45

Data Analysis............... . . 46

IV. Results... . . . . . . . . . . . . . . . 48

Demographic Characteristics . . . . . . . . 49

The Research Questions . . . . . . . . . 50

Content Analysis . . . . . . . . . . . 56

v. Discussion . . . . . . . . . . . . . . * 63

Limitations of study . . . . . . . . . . . 71

Recommendations............. . . 73

Nursing Implications . . . . . . . . . . 74

Summary ................ . . 76

VI. References...... . . . . . . . . . . . . 78 
VII. Appendices

APPENDIX A . . . . . . . . . . . . . . . . .

APPENDTX B *. . . . . . . . . . . . . . . . .

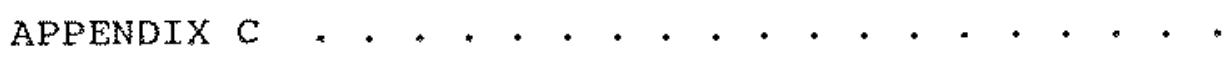

APPENDIX D . . . . . . . . . . . . . . . . . . . 95

APPENDIX E . . . . . . . . . . . . . * * 96

APPENDTX F . . . . . . . . . . . . . . . . . . . 97

APPENDIX G * . . . . . . . . . . . . . *.. . . . 99

APPENDIX H. . . * . . . . * * . . . * . . * 112

APPENDIX I. . . . . . . . . * . . . . . . 113

VII. Consents and correspondence

CONSENT I. . . . . . . . . . . . . . . . . . . . 114

CONSENT TI * . . . . . . . . . . . . . . . . . . 115

CONSENT III. . . . . . . . . . . . . . . . . 116

CONSENT TV . . . . . . . . . . . . . . . . . . . 117

CONSENT V . . . . . . . . . . . . . . . . . . . . . 118

CONSENT VI . . . . . . . . . . . . . . . . . . . 119 


\section{List of Tabies}

Table Rage

I. Survey questions by Collaboration Factor. . . . . 40

II. Comparison of Demographic Results. . . *. . . . 50

III. Pearson's product Moment Correlations of Survey

Factors and Demographics..... . . . . 52

IV. Perceptions by Collaboration Factors. . . . . . 54

V. Two Tailed t-test Difference between Means of

Emergency Roorn Nurses and Paramedics.. . . 55 
Chapter 1

Introduction

\section{Problem Area}

A person's first contact with the health care system is often through the emergency medical system (EMS) and/or the emergency room. The meeting is usually due to a "misfortune" of the patient. It is emergency room (ER) nurses and the paramedics that care for the patient as first responders as part of the health care system.

The prehospital management of critically ill patients by paramedics is a relatively new concept in the medical field and unique to the United states. In other countries that provide prehospital life support, the services are administered directly by physicians (Caroline, 1983). Beginning in the late 1960s, an alternative to the physician staffing the rescue vehicle was developed as the role of the paramedic (Caroline, 1983).

The history of the use of emergency personnel dates back to the time of the Napoleonic waxs when light carriages were used to transport the injured (Palmer \& Gonsoulin, 1990). This system was used until the industrial revolution when the development of the automobile was introduced. The arrival of the paramedics in the early 1970 s was prompted by several social, technological and medical 
events. These events include: (1) the development of high speed vehicles and highways in the 1950 s and 1960s, which resulted in the increasing number of fatal accidents, publication of a National Academy of Science/National Research CounciI "White Paper" (1966) which described a sordid picture of emergency health care in the U.S., (3) passage of the National Highway Safety Act in 1966 requiring prescribed levels of emergency response along the highway systems in order to qualify for continued federal highway monies, (4) the organization of the National Registry of Emergency Medical Technicians in 1970 , (5) the creation of residency program for emergency physicians by the American College of Emergency Physicians in the mid-1970s, and (6) the return of vietnam veterans trained in trauma treatment and having experience in flying helicopters (Palmer \& Gonsoulin, 1990).

This occupational blossoming has not occurred without it's share of obstacles. Uncertainty of objectives and functions, rapid growth, frequent policy modifications, poor image, and hesitancy of acceptance by medical professionals contributed to job instability (Palmer \& Gonsoulin, 1990). Initially, paramedics were limited to minor treatments and transportation, but now with the advances in medical care, the role of the paramedic is expanding. This expansion includes skills that ER nurses and physicians perform such 
as intubation, interpreting electrocardiograms and the administration of thrombolytic agents.

The standard for the actions of the paramedics was originally found in the historical concept of the "Good Samaritan", where an individual is protected form liability when rendering aid to another in a prudent fashion (Palmer \& Gonsoulin, 1990). Current practices are now more complex. The paramedic provides emergency interventions and life saving maneuvers with the use of skills and protocols mandated by the state in a prehospital environment. Legal precedent for the actions of the paramedic is lodged within each state's medical practice act which specifies standards of care and the procedures that EMS providers, at all levels, may preform.

The focus of paramedic education is on short term care providing emergency interventions and brief medical treatment with safe transport of the critical patient to the emergency room, in contrast to, nursing education which has placed emphasis on the prevention of illness, pathology and treatment of both acute and long term problems, and rehabilitative care (stewart, 1990). Registered nurses have trained more intensively and for a greater duration of time encompassing broader aspects of patient care. This includes biological, medical, psychological, developmental, social, cultural as well as holistic approaches. These differences 
in educational goals and skills frequently causes disharmony between the paramedic and the emergency room staff.

Paramedics deal with a variety of medical and non-medical occupational duties. The services are provided within a surrounding of medical protocols made up of "dull" as opposed to "trauma" runs. Many thrive on the psychological "high" or "adrenalin rush" associated with the rescue and the life saving environment. The paramedics are rewarded on how they execute extrication, packing, transporting and delivering the emergency patient in the shortest period of time. Therefore, they depend on an increasing number of exciting "runs" to validate their role as a paramedic. Upon arrival to the emergency room the paramedics want a quick, smooth transfer of the patient so they can return to service. Palmer (1983) describes this phenomena:

Paramedics and emergency medical technicians develop a need for role validation associated with the ambulance runs that call forth advanced lifesaving, rescue and medical skills. Metaphorically, this need turns paramedics into "trauma junkies", . because answering calls involving multiple casualties, physical trauma, and fast paced action becomes the "real" work of emergency medical service personnel. calls evoking less sophistication of response behavior are devalued.

The quick paced philosophy of the EMS service along with the educational goals frequently cause friction the relations between the paramedic and the energency room 
personnel (Palmer \& Gonsoulin, 1990; Stewart, 1990). The process of managing and transporting criticaliy ill patients to the emergency department demands communication and cooperation. If the process is complicated by miscommunication, competition, disagreement, and different perspectives toward patient care, the outcome for the patient can range from uncomfortable to disastrous. Interpersonal communication and collaboration between ER nurses and paramedics is the key element in the smooth transfer of patients from the prehospital emergency medical system to the hospital system.

\section{Problem statement}

The recent expansion of the role of the paramedic to include administration of thrombolytic agents and other high technological procedures has developed rapidly. This new growth along with the differences in education of the paramedic, creates friction and dissension among the personnel. In their 1988 study on the work-stress burnout among paramedics, Grigsby \& Mcknew found that negative interpersonal relationships with coworkers and emergency room personnel and certification requirements, produced the two highest correlations with the burnout measure. Communication and teamwork are essential among emergency 
personnel in order to provide congruent and quality patient care.

Collaboration is the relationship between associates of different professions working together toward mutual goals (Homonofe Maltz, 1991). In this case, the goal is to provide high quality care to the patient. ER nurses and paramedic work jointly to provide quality care to a patient in emergent situations but in distinctively different work settings with different occupational and educational frameworks.

Numerous organizations support collaborative practice among health care professionals. The American Medical Association (AMA) jointly sponsored the National Joint Practice Commission which was a task force to explore boundary issues between nursing and medicine. In 1981, the commission was dissolved and they published "Guidelines for Establishing Joint or Collaborative Practice in Hospitals" (Morgan \& McCann, 1983). The American Hospital Association (AHA) supports the concept that hospital administrators should be activity involved in joint practice to help physicians and nurses attain a level of practice acceptable to them, to their institutions, and to the comittees they serve.

The American Nurses Association (ANA) in the 1980 Social policy statement defined collaboration as a "true 
partnership in which the power on both sides is valued by both, with recognition and acceptance of separate and combined spheres of activity and responsibility, mutual safeguarding of the legitimate interests of each party, and a commonality of goals that is recognized by both parties" (American Nurses Association, 1980). The ANA continues to support collaborative practice among nurses and among all health care providers.

Even though, there is a collective belief that collaboration is a concept that is significant for health care, the policies or statements have not been incorporated into practice by the providers. Therefore, the focus of this study is the perception of the collaborative relationship between $\mathrm{ER}$ nurses and paramedics.

\section{Purpose}

The purpose of this study is to examine the nature of collaborative relationships between ER nurses and paramedics in Southern Dade County, Florida. The focus includes:

1. investigating the relationship between selected demographic variables and collaborative perceptions.

2. investigating the differences in collaborative perceptions between ER nurses and paramedics.

3. identifying contextual factors in the collaborative relationship. 
Interpersonal communication is most prominent during the "report" of patient information from paramedic to ER nurse. Interdisciplinary collaboration is needed to provide quality patient care and promotes fellowship among the departments.

Research about the collaborative relationships among health care professional is limited; with research on the interaction of paramedics and emergency room nurses almost obsolete. This study expands the existing literature and provide future area of research.

\section{Research Question}

The research question proposed for this study is: What is the nature of the perceptions of the collaborative relationship between emergency room nurses and paramedics? It has been shown that interactions between nurses and physicians and nurses and paramedics are generally positive but each profession is more likely to interact among thenselves. Limited interaction undoubtedly contributes to poor communication between the professions. This study looks at the nature of collaborative relations via the following study questions:

1) What effect does the personal attributes of age and gender have on the perceptions of the collaborative relationship between ER nurses and paramedics? 
2) What effect does the social demographics of experience and level of education have on the perceptions of the collaborative relationship between ER nurses and paramedics?

3) What are the differences in the perceptions of the collaborative relationship between ER nurses and paramedics?

4) What axe the contextual factors in the collaborative relationship between $\mathrm{ER}$ nurses and paramedics?

\section{Study Variables}

The main study variable is the collaborative relationship which includes the following study variables: Personal attributes, social demographics, positive interaction, active participation, equality of influence, and shared responsibility and accountability.

personal attributes for this study include age and gender of the nurses and paramedics. Social demographics for this study include years of experience as a paramedic, not including emergency medical technician (EMT) experience and level of education, These items will be collected in part I- Denographics

Positive interaction, active participation, equality of influence, and shaxed responsibility and accountability wi11. be determined by the collaborative Practice Perception scale. The obstacles or areas of conflict will be defined per the participant in the Free Response section of the questionnaire. The Free Response area will also identify those contextual areas of collaboration not previously 
identified in the review of literature or in the survey section.

\section{Assumptions}

1) Collaboration is enhanced when there is open communication, positive interaction, active participation, equality of influence, and shared responsibility and accountability.

2) Open communication is essential for the transfer of information and assists in maintaining the contimity and quality of care of the patient.

3) Health professionals have a responsibility to share information that helps individuals make informed decisions about their health care ( $\mathrm{King}, 1981$ ).

4) Perceptions of the nurse and the paramedic influence the interaction (communication) process (King, 1981)

5) Goals, needs and values of the nurse and paramedic influence the transaction process (report) (King, 1981).

\section{Definition of terms}

Authority a transactional process characterized by active, reciprocal relations in which members" values, backgrounds, and perceptions play a role in defining, validating, and accepting the directions of individuals 
within an organization (King, 1981, p.124).

Collaboration- a practice that involves interaction between individuals or groups that enables the knowledge and skilis of both professions to synergistically influence the patient care being provided (Weiss \& Davis, 1985).

Communication- an information processing, a change of information from one state to another (King, 1981, p.69). It is a process by which information is transmitted through a common system of symbols, signs or behaviors (Haber, 1982).

Decision-making- a dynamic and systematic process by which a goal-directed choice of perceived alternatives is made, and acted upon, by individuals or groups to answer a question and attain a goal (King, 1891, p.132).

Interaction- a process of perception and communication between person and environment and between person and person, represented by verbal and nonverbal behavior that are goal-directed (King, 1981, p.145).

organization a system whose continuous activities are conducted to achieve goals (King, 1981, p.119). It is composed of human beings with prescribed roles and positions who use resources to accomplish personal and organizational goals (King, 1981, p.119).

Berception- a process of organizing, interpreting, and transforming information from sense data and memory (King, 
1981, p.24). It is each person's representation of reality; awareness of persons, objects, and events (King, 1981, p.146).

Rower- a capacity to use resources in organizations to achieve goals; a process whereby one or more persons influence other person in a situation; the capacity or ability of a group to achieve goals (King, 1981, p.124).

Role- a set of behaviors expected when occupying a position in a social system (King, 1981, p.93).

Status- the position of an individual in a group or a group in relation to other groups in an organization (king, $1981, p .129)$.

Iransaction- a process of interaction in which human beings communicate with the environment to achieve goals that are values (King, 1981, p.82).

Prehospital- any area in which emergency medical services are provided priox to admission to the hospital emergency room.

Raramedicsm persons who have completed the. requirements for licensure and have passed the examination given by the state and that have worked in a prehospital environment for at least one year.

Registered nurses $=$ persons who have completed the requirements for $R+N$. licensure and have passed the state licensure examination. Emergency nurses are registered 
nurses who have worked in the emergency roon setting for at Least one year.

continuify of care- the logical, smooth flow of care of the patient from the time they enter the health care system through being discharged home (Tappen, 1983 ).

\section{Significance}

The use of "911" calling system has helped in'saving many lives by rapidiy providing emergency care. The elevated number of critically ill patients entering the emergency room has made the communication between the nurses and paramedics even more vital.

Collaboration is an important aspect of any working relationship and is enhanced when there is open communication. Good communication and working relationships with paramedics contributes to nursing by providing a pleasant and trusting working environment. This benefits the patient by furnishing a smooth transfer from prehospital to hospital care when the patient is unable to care for himself. Research in the area of prehospital care and emergency nursing is crucial due to the increasing number of patients using the emergency medical system.

Patient pexceptions of the emergency experience are formed during encounters with the emergency personne1, the hospital and the rescue system. Hospitals have become 
increasingly concerned with consumer responses to the care given because it is important in recruiting patients for future visits. Dortar (1993) documents the practical benefits of collaboration to hospital administrators is shown by increased consumer satisfaction.

Eubanks (1991) states that hospital chief executive officers (CEOS) have been concerned with the quality of patient care. The cEOs have observed that the solution is immersed in the relationship between nurses and physician as well as all the other disciplines within the hospital. This issue has recently become of interest because of the changes in the health system. The success of individual hospitals will be linked to the ability of each institution to facilitate the nurse-physician relationship. Hospitals that succeed in improving this relationship will thrive; those that do not will lose nursing employees, admitting physicians, ana, ultimately patients (Eubanks, 1991).

Teamwork is the process by which a group of people work together towards a common goal (Tappen, 1983). It requires a degree of cooperation and communication with others. Communication by positive feedback, documenting and recognizing that a job has been done well, increases self esteem which affects job satisfaction and job retention. Communication maintains the continuity of care and allows 
the nurses and paramedics to contribute to the total health care system.

Nursing Implications

Prehospital care is a rapidly expanding area of health care and is the gateway for many patients into the health care system. Strong cooperation is necessary to provide guality patient care. The benefit of this study to nursing practice consist of increasing the awareness of the emergency nurse and paramedic to the collaborative practice between the professions. This increased perception will benefit the quality of patient care due to increased teamwork and a sense of continuity. Collaborative endeavors assist in creating a pleasant and trusting working environment. The final and most significant benefit is the increased awareness that ER nurses and paramedics have a similar occupational goal in caring for the well-being of the acutely ill patient.

A survey of the literature indicates the need for maximum voluntary collaboration by emergency nurses and paramedics is critical. Nurses and paramedics continue collaborative efforts in an unstructured manner. Therefore, their success in achieving a substantial impact in enhancing the relationship is minimal. This study will help to increase the awareness of collaboration and identify areas 
of confict in the present interactions of emergency nurses and paramedics. These identified areas can be addressed in nursing education when discussing the roles of other health care professionals. Closer collaborative practice between nursing education and other health care professionals is essential to give students, both nursing and paramedic, a prospective of the various roles within health care and a complete representation of the patient's care from" prehospital through admission to the hospital and eventually discharge home.

The primary benefit of this study to nursing research is expanding the knowledge regarding the interactions between ER nurses and paramedics. Providing information on areas of conflict in communication between $E R$ nurses and paramedics is crucial in promoting a collaborative relationship.

The literature defines collaboration and describes collaborative practices but there is a paucity in means to measure it's components. In 1988, pehl developed a'tool to measure collaboration between nursing service administrator and nursing practice. The study uses this new tool, revised for a clinical setting with emergency nurses and paramedics to assist with the validation of the tool. Nursing research on the construct of collaboration is significant because collaboration is vital in all working relationships. 


\author{
Chapter 2 \\ Review of the witerature
}

\title{
Introduction
}

The concept of collaboration within the nursing profession has been explored with physicians in the academic setting, within multidisciplinary conferences, and among nurses but little is known about the relationship between nurses and paramedics. This review of literature will present, in the following order, findings related to competition and cooperation, nurse-physician collaboration, nurse-physician conflict, collaboration among nurses and other health care professionals, and nurse-paramedic interactions.

Competition and collaboration

Some of the earliest research of the effects of cooperation and competition was complete by Morton Deutsch in 1949. His studies showed that there was a higher degree of coordination, friendiness, and productivity in cooperative groups than in competitive ones. This outcome has been reported by other researchers (Hammond \& Goldman, 1961; Jones \& Vroom, 1964; Klein, 1956; Mintz, 1951; Myers, 1962 ; and Napier \& Gershenfield, 1973). Napier and Gershenfield (1973) points out that a 
competitive and hostile climate is likely to result whenever people who are engaged in problem-solving feel that the other side wants to reduce their power. Hellriegel and Solcum (1974) presented a summary of the consequences of competitive and cooperative intexpersonal relationships. The result of competitive relationships revolve around antagonism and power minimization; suspicion and hostility; separation of interests; and misleading communication. On the other hand, cooperative relationships emphasize interest and power enhancement; trust and responsiveness; sensitivity to common interests and convergence of beliefs; and accurate communication.

Kolb, Rubin, and McIntyre (1974) outlines three of the consequences of utilizing competitive strategies. They are:

1) The development of a competitive, win-lose climate that emphasizes the separateness of "we" and "they" and feeling that "we" are superior and "they" are inferior. Individual factions or groups under competitive pressure invariably rate themselves above-average in both cohesion and ability.

2) Distortions in judgement. Individuals or groups under competitive pressure invariably evaluate their own contributions as best, and fall into downgrading efforts of others.

3) Distortions in perception. Experiments demonstrate that under competitive pressure pexsons perceive that they understand the other persons' proposal. when in fact they do not. Consequently, areas shared in common are likely to go unrecognized. 
In sumary, then, cooperative groups exhibit the following characteristics:

1) More effective intermember comunication.

2) More friendliness, more helptulness, and less obstruction.

3) More coordination, more division of labor, more orientation to task achievement, more orderisness in discussion and higher productivity.

4) More feeling of agreement and similarity of ideas, more confidence in one's own ideas and in the value others attach to those ideas (Deutsch, 1973).

The competitive values system has emerged from hundreds of years of thinking has become deeply webbed into our beliefs about the nature of conflict. Confilct in organizational settings has its core in the competition over something perceived to be scarce. Status, prestige, power, and influence are among the resources perceived to be scarce (Kraus, 1980). This perceived scarcity continues to reinforce competition and teaches competition as a positive value system instead of collaboration.

Collaboration between Physicians and Nurses

Literature about collaboration between physicians and nurses have been in the area of cooperative learning in the academic setting. Numerous research studies have addressed the collaborative relationship between nuxse practitioner 
students and medical schools. A cooperative effort between a school of nursing and a university hospital department of medicine was initiated to educate acute care nurse practitioners. Nurse practitioners were responsible for case management of patients in collaboration with physicians. Results showed promise for interdisciplinary patient management and nurse-nurse and nurse-physician collaboration (Shah, Sullivan, Lattanzio \& Bruttomesso, 1993).

LeRoux, Gutierrez \& Todaro (1993) describes the collaborative role between a university school of nursing and a medical center for a perinatal nurse practitioner program. The study shows effective collaborative practices within an academic setting. Williams (1993) recounts the development of the Texas Medical Center collaborative Preceptor Program, which also shows collaborative practices within a university setting. Most of the collaborative research performed within the academic arena has been effective because research and education is the primary focus.

Torgersen \& Chamings (1994) looked at the collaborative pexceptions that anesthesiologists and nurse anesthetists have on each other in nurse anesthesia educational programs. Results highlight important areas of conflict between the two groups including unequal and hierarchical relationships 
regarding shared responsibility, access, power, and recognition in health care decision-making. The study also noted definite philosophical and political differences between the two groups.

Collaboration between groups with similar occupational descriptions becomes strenuous because of possible role confusion, such as with the nurse anesthetist and the anesthesiologist. This role strain leads to competition and conflict.

\section{Nurse-physician Confict}

Morgan and Mccann (1983) discusses the historical perspective of the nurse-physician relationship. Conflict between the male physician and the female healer has been identified as early as the 13 th century when the first European medical schools appeared. By the 14th century, there was a great demand for university trained physicians and "well-to-do" young men flocked to the universities to become doctors. Women at that time were almost universally excluded from medical schools and licensing laws appeared that prohibited the practice of medicine by anyone except the university trained physician. Many of the lay healers were women and women who dared to cure without a iicense was considered a witch and put to death (Morgan \& Mccann, 1983). Throughout history nursing has gone through three 
ideologies. With "Nightingalism", the nurses were considered the hand-maiden of the physician and with patexnalism, the hospital played the role of the father figure or "big daddy". At present, professional collectivism is in progress with nurses banding together to determine their own working conditions and quality on nursing practice. Even with this last evolution, the are many physicians who continue to view nursing as an extension of medicine and not a discipline in and of itself (Morgan Mccann, 1983).

The educational gap between physicians and nurses creates a barxier in the relationship. Holkelman (1975) recognizes the difference in educational preparation and the fact that physician and nurses place different values on specific areas of health care continum. This difference in emphasis continues to be a source of communication difficulties.

Campbe11-Meider \& Pollack (1988) looked at barriers to physician-nurse collegiality from an anthropological perspective. They found that the hierarchial framework of health care requires that a single individual be ultimately responsible, legaliy and clinically to manage the patient's care. Physicians occupy that role which cause nurses to be viewed as physician extenders or helpers. often emergency nurses feel that they are responsible for the patients care 
once the patient enters the hospital and may view the paramedics as the nurse's helper.

Researchers have identified the sources of nursephysician conflict (Kalish \& Kalish, 1977), the consequences of ineffective communication (Prescott \& Bowen, 1985), and means of interaction (Kennedy \& Garvin, 1988). It has been shown that interactions between nurses and physician are generally positive but physician are more likely to interact with other physicians and nurses are more likely to interact with other nurses (Kerr, 1986). Limited interaction undoubtedly contributes to poor communication between the professions. This communication pattern is similar to nurse-paramedic relations and therefore may apply to the situation.

Collaboration between Nurses and other Health Professionals Cooperation is a key issue when there is collaboration between nurses and other health professionals. Cooperation and collaboration are components of collegiality.

Collegiality is the professional relationship between two or more persons in the same profession who share equal power and authority and work together or participate in reaching similar goals (Beyer, 1981). Several studies have noted the need for collegial relations among nurses (Beyer, 1981; Beyer \& Marshall, 1981; Dick, 1986; MCMahon, 1990) and 
interdepartmental collegiality Carroll, 1987; Iles \& Auluck, 1990; Williams, 1985). In all studies, it is agreed that collegial and collaborative relations are important in providing a good working enviromment. Dick (1986) specifically reported a relationship in collegiality decreasing burnout among nurse faculty. Campbel1 \& Dowd (1991) showed that collaborative projects improved collegiality and decreased intrapersonal conflicts:

\section{Nurse-Paramedics Interaction}

C. E. Palmer has studied the occupational behavior of paramedics and emergency medical technicians (EMT'S) for the last 10 years. Palmer (1983) examined paramedics and EMT's from an ethnographic concern as providers of emergency care and in articulating the flow of urban excitement of this occupational subculture. The data was collected by participant observation, informal interviews, conversation, listening to official radio traffic, and inspection of written documents. The majority of the data was obtained on the 490 hours spent with EMS persomel attending to 88 rescue calls. He concluded that with the occupational axena of excitement and danger, the paramedic performs a variety of roles constituting street work similar to police officers. These roles include authority figuxe, lifesaver, information specialist, partner, grief manager, and 
counselor. Due to the newness of their medical function, paramedics are immersed in a work world abundant with teamwork demands, conflicts with medical and nonmedical personnel and vaguely defined legal standards.

A more recent research study by palmer and Gonsoulin (1992) examines the nurse-paramedic interaction. This was an exploratory study in which structure interviews were conducted with 35 persons $(21$ paramedics and 12 full-tine ER nurses and $2 \mathrm{gD}$ physicians). The interviews ranged from $30-$ 80 minutes. They focused on the general relationship and then on conflict as the basis of how the two groups interact. The researchers reported that open conflict between the nurse and paramedic are not frequent, but do occur. The primary area of conflict is the report from the paramedic to the nurse.

Many of the paramedics felt that they were not being istened to, or the nurse did not value the paramedic's assessment of the patient. Or if the paramedic was heard, they may be challenged as to the care given or their level of competence. They also claimed that they face numerous insults to thejr occupational identities such as being a "less than capable" nember of the trauma team. They telt that the nurses had "superior attitudes" or thought of the paramedics as "peons" or "just ambulance arivers".

Some of the paramedics felt that there was confulut 
because the nurses might be jealous of the roles paramedics play during trauma or emergency cases or of skills the paramedics are allowed to preform such as intubation. The paramedics reported that they believed that the ER nurses did not appreciate the time constraints or the working conditions in which they must provide care.

on the other hand, emergency nurses felt that the paramedics did not know when their medical control had ended once the patient had been brought to the ER. The nurses also admitted that they sometimes acted in a "condescending manner" toward those they thought were inferior in knowledge and skills. The most common responses reported from the nurses were related to the quality and type of patient care. The attitudes and behaviors of the nurses and paramedics are affected by the training individually received which influence their interaction during the time of transfer. Palmer \& Gonsoulin (1992) associated the power struggles and "turf wars" to the educational goals and training which produces different occupational perspectives. When the nurse and paramedics are on different tracks or wavelengths, and negative situations persist over time, relationships can degenerate to the point of harm for the patient. 
Summany

Research examines the collaborative relationships between physicians and nurses, between nurses, and between other departments in the hospital. There is evidence in the literature that demonstrates that the relationship between nurses and physicians has dèvloped over a long period of time and has adapted to alterations in society. Even though nuxsing is an evolving profession, there are many physicians who continue to view nursing as an extension of medicine and not a discipline in and of itself (Morgan \& McCann, 1983).

The review of the 1.iterature on the interaction between paramedics and nurses or on interventions that may improve collaborative relationship has been scarce. prehospital care is the newest emerging profession and occupies a role which is often viewed to be nurse extenders or helpers, especially in the emergency room. These concepts can create conflict which sabotages a collaborative relationship.

Theoretical Framework

King' Conceptual Framework for Nursing

Imogene King's conceptual framework for nursing is the theoretical foundation for this thesis and can be implemented in examining the relationship between nurses and paramedics. King utilized the general systems theory to 
provide a structure for nursing as a discipline and a profession. The framework is grouped into three dynamics interacting systems: 1) personal system, 2) interpersonal system and 3) social systems.

A personal system is viewed by King as an individual, utilizing information that would assist nurses in understanding individuals. A human being is a complex, open living system that react to their environment on the basis of their perception, expectations, and needs. The concepts of body image, growth and development, perception, self, space and time are relevant to the personal system.

Interpersonal system focus on groups of individuals including dyads, triads, and small or large groups. Communication, interaction, roles, stress, and transaction are concepts more important to the interpersonal system.

King (1981) defines a social system as an organized boundary system of social roles, behaviors and practices developed to maintain values and the mechanism to regulate the practices and rules. Individuals within a social system share common goals and interests. Within the social system, the concepts of authority, decision-making, organization, power and status are utilized. In summary, an individual functions in social systems through interpersonal relationships in terms of perception which influence decisions regarding life and health. 
Although King's concepts are placed in specific systems, they are applicable to each system due to the interrelation of the three systems. In examining the ER nurse-paramedic relationship, the concepts of authority, communication, decision-making, interaction, organization, perception, power, roles, status, and transaction are the most applicable in combining King's theory with the collaborative process.

In using King's general system framework where personal perceptions, intexpersonal interactions and societal systems affect each interaction, the collaboxative practices of paramedics and emergency nurses can be examined. The structure of the theory indicates some semipermeable boundaries of two or more individuals interacting in the health care system for the purpose that leads to a goal (Riel-Sisca, 1989). This element of interaction is connected by communication in a shared collaborative process. In this case, paramedics share information regarding the client's prehospital care and then collaborates with $\mathrm{ER}$ nurses to move toward the mutual goal of quality care for the patient.

If the interaction is positive, the nurse and paxamedic feel a sense of camaraderie and the transaction is smooth. If the interaction is negative, the nurse or the paramedic may have interpreted the conflict as personal (individual 
paramedic with individual nurse), interpersonal (cextain rescue station with a certain emergency room), or organizational (ali paramedics with all Ek nurses). This is consistent with $\mathrm{King}^{*} \mathrm{~s}$ eramework.

The environment along with personal characteristics influence responses to a situation. Each persons perception varies aue to differences in their backgrounds, skills, abilities and values. All these points are incorporated to the communication patterns of a person.

\section{Comunication/Perception Theory}

There is vexy little documentation on the communication patterns between the nurse and paramedic. Commuication is a process by which information is transmitted through a common system of symbols, signs or behaviors (Haber, 1982). It involves an interaction between 2 people who comact upon or affect each other. The interaction is simultaneous and flows in both directions.

The cixcular model of communication illustrates that communication incluctes a sender, a message, a receiver and feedback in a cixcular pattern (Haber, 1982). It is simplistic but contains the essential components of communication. Feedoack is important in maintaining communication because it is both the mechanism and cxiterion by which our effectiveness is determined (Hein, 1973). 
Positive feedback is a helpful source of information that reinforces our successful effort and reaffirms our expectations (Hein, 1973).

Comunication is an important aspect of any collaborative working relationship. Studies have shown that adequate flow of information between people who are working together is necessary for smooth operation and for preventing misunderstandings. Also, people are more likely to exchange information when there is a sense of collaboration.

\section{Collaborative Eramework}

Collaboration, used broadly, denotes one person working with another towards a mutual goal. The collaborative models for this study, have been examined within physician relationships and organizations.

Despite testimony to the valve of cooperative efforts, their is continuing evidence of a significant discrepancy between the concept and practice of collaboration. Researchers have examined the relationship between pediatric psychologist and pediatricians. They found that when physicians and psychologists do work together their interactions are disrupted by misunderstanding, conflicts of interest or struggles for control even when such 
collaboration who be helpful to the client (Dortar, 1983; Miller \& Schwartz, 1990).

Dortax (1993) addresses the need for a comprehensive framework that describe the broad range of professional interactions. He defines interdisciplinary collaboration as any professional activity conducted between members of one profession and another. Collaboration is heavily affected by the individual characteristics of the colleagues and their settings. Three factors influence the initial. decision to collaborate which include: 1) participant's beliefs about the need for and expectations of collaborative outcomes; 2) participants knowledge, skills and priox experience in collaborative activities; and 3) setting-based barriers and supports. This framework suggests that collaborative success will increase as the skills, beliefs and incentives for collaborations become inherent to practice.

Summary

King's conceptual framework and goal attaiment theory are the developmental components of collaboration. Individual collaborative practice incorporates all of the past experiences, judgements and perceptions of the working encounters with the other person or agency. These thoughts and experiences influence future interactions and can either 
enhance or diminish the relationship.

Nurses and paramedics interact during the patient report where there is not only a txansfer of information but the transfer of power and authority. Palmer and Gonsouitin (1992) examined the nurse-paramedic interaction and found that open conflict between the nuxse and paramedic are not frequent, but do occur with the primary area of conflict is the report from the paramedic to the nurse.

Within King's framework, interaction, communication, power, and authority are defined concepts which are interrelated in the interactions of human beings within their enviromment. Purposeful interactions require that the nurse and paramedic openly share information and agree on the means to achieve goals. By being open to cues given auring the interaction, each participant is more able to process information (King, 1981).

collaboration denotes one person working with another towards a mutual goal working environment. Purposeful, goal-oriented interaction among nurses and paramedics enhance the effectiveness of care and create positive outcomes for those involved. This is consistent with King's goal attainment theory along with the collaboration framework. 
Chapter 3

Methodology

Desjan

A correlation descriptive study tas used to examine the perception of the collaborative relationship between ER hurses and paramedics. Polit and hungler (1991) describes correlational research as the exploration of interrelationship among variables of interest without any active intervention from the researcher and descriptive research as the accurate portrayal of characteristics of persons, situations, or groups and the frequency of occurrence. This was the most appropriate design to investigate and describe the possible relationship between the pexceptions of collaboration between ER nurses and the paramedics and age, gender, level of education and experience.

Sample

The target population for this study was licensed paramedics working in a prehospital setting and registered nurses working in the emergency room setting. The subjects were obtained from a convenience sample of ER nurses and paramedics working in the southern part of Dade county* The subject selection was not based on age, gender or minority status. Excluded from the study were paramedics 
and ER nurses that have been employed for less than one year due to Iimited interaction with each other, and persons who are both a nurse and paramedic due to the conflict in interest by being both a registered nurse and paramedic.

The paramedics were employed by the county emergency medical system. The paramedic sample contained paramedics from each shift $(A, B$, and $C)$. The paramedics work 24 hours on duty and 48 hours off, therefore, the first 24 -hour shift is the "A" shift, the second 24 -hour shift is the "B" shift and the third 24 -hour shift is the "c" shift.

The paramedics population in Southern Dade county was 100. This figure was obtained by contacting the Division Chief's office requesting the number of paramedics staffed at each station. This included 9 paramedics and 1 swing paramedic per station. The surveys were distributed by the Division's Special Assistant to the officer in Charge at each station, who then distributed the surveys within their respective stations. There were no undistributed surveys

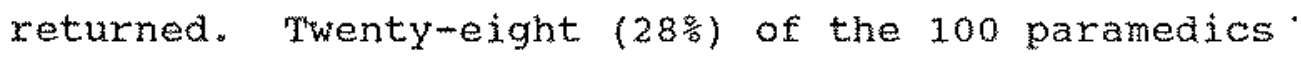
responded. Out of these 28,2 paramedics wexe dropped from the survey because the were both registered nurses and paramedics. Therefore, only 26 surveys were included in the study.

The nurses were employed at local private community hospitals in Southern Dade county. whese are commity 
hospitals where the county fire Rescue paramedics transport theix patients. Nurses from each institution and each shift were used.

The emergency nurse population in southern Dade county was 116. This figure was obtained by contacting the ER nurse managers of each of the participating hospitals and requesting the number of nurses staffed. The surveys were distributed by the nurse managers within their respective emergency rooms. Eleven undistributed surveys were returned upon completions of the study period, 7 surveys from one emergency room and 4 from another. Twenty-three (22\%) of the 105 emergency room nurses responded. Out of these 23,2 were dropped from the study because the survey was returned incomplete. Therefore, only 21 surveys were included in the study.

\section{Informed consent}

To ensure protection of human rights of the participants, the following protocol was followed. A cover letter (Appendix A) was provided to the participants introducing the investigatom and the study. The risks, benefits, rights and responsibilities of participation were outlined. The participants were instructed that they had the righ to refuse participation or withdraw from the study at any time without penalty. The letter provided assurance 
regarding confidentiality and voluntary participation.

Informed consent was incorporated into the cover letter with the completion and return of the survey indicating consent of participation. Data collection commenced after approval in writing from the Research and Human subjects comittees of Florida International University, the Medical Centers and the County Fire Rescue (Consents I-IV).

\section{Instrument}

The research instrument that was used in the study consists of three parts: 1) General Demographic Information (Appendix B), 2) Revised Pehl Collaboration Scale (RPCS) (Appendix $C$ ), and 3) Free response questions (Appendix D). Part 1 was developed by the investigator to collect demographic data for grouping of persons on personal and organizational variables that may influence collaboration. Emergency room nurses where asked to supply age, gender, basic level of nursing preparation, highest degree held, years since graduation from their basic nursing program, and years as an emergency room nurse. Paramedics were asked to supply age, gender, basic level of paramedic preparation, highest degree held, years since graduation from their basic paramedic program, and years on the county Fire Rescue.

Part 2, Revised Pehl Collaboration scale (RPCS), was 
modified from an established instrument called the peht Collaboration scale developed by finda penl in 1988. The original instrument was based on a concept analysis of collaboration completed by pehl and was designed to measure collaboration as perceived by nursing deans and nursing service administrators. It was used with permission by Linda Pehl (Appendix E).

For use in this study, the investigator modified Peni's Collaboration Practice Scale. There were 12 items that were not related to clinical practice such as curriculum issues, joint employment and specific educational objectives that were eliminated. mhe uneven distribution of the items on the original collaboration scale were due to the significance of the components identified in the concept analysis. The percentage of items eliminated from each factor was constant, therefore dia not skew the original distribution. The ordex of the items on the survey have not been changed and no new items have been added. The wording Was moditied on the RPCs to make it appropriate for use in clinical practice (in this study, for use with ER nurses and paramedics)

The RPCS consists of 38 items related to perceptions of collaborative practice which separate into four domains. Domain 1: positive Interaction-consists of 16 items related to sharing, mutual trust and respect, open communication and 
exchange of information. Domain 2: Active Participationcontains 7 items relating to joint forces, depending on each other"s skilis and knowledge, interdependence, joint decision making and unified goal achievement. Domain 3: Equality of Influence-consists of 8 items related to power on both sides valued by both ER nurses and paramedics, recognition/acceptance of separate and combined spheres of influences, mutual safeguarding of legitimate interests of each party, equal input and partnership, and reciprocal respect. Domain 4: Shared Responsibility and Accountability-consists of 2 items related to accountability and responsibility. Table $x$ displays the survey questions by collaboration factors. 
Table I

SURVEY QUESTIONS BX COLLABORATION FACTOR

\section{EACTOR I- POSITIVE INTERACTION}

11. Confidence and trust should exist between ER nurses and paramedics.

13. ER nurses and paramedics should feel free to exchange ideas and opinions.

19. ER nurses and paramedics should share information about important events.

20. ER nurses and paramedics should share continuing education programs and educational software.

21. ER nurses and paramedics should socialize new nurses/paramedics into the professional role.

22. ER nurses and paramedics should have an opportunity to experience each others professional roles.

23. ER nurses and paramedics should work together on joint research projects.

24. Provisions should be made for feedback of interagency information via newsletter, memos, or patient updates.

25. There shculd be utilization of ER nurses and paramedics as role models for nursing and paramedic students.

28. There should be a consensus between the professional goals of ER nurses and paramedics.

29. ER murses and paramedics should participate in joint committees.

30. The should be cooperative orientation activities between new ER nurses and new paramedics.

31. ER nurses and paramedics should explore issues related to educational programs together.

32. ER nurses and paramedics should explore patient care stariards together.

36. Strategic long-term planning should be carried out between ER nurses and paramedics. 
10. ER nurses and paramedics should work together as a team toward patient care goals.

12. ER nurses and paramedics should coordinate their efforts.

14. ER nurses and paramedics should cooperate for achievement of patient care goals.

15. ER nuxses and paramedic should welcome information from each other.

16. ER nurses and paramedics should be willing to share knowledge and lend assistance to each other.

17. ER nurses and paramedics should deal with conflict openly.

18. ER nurses and paramedics should hold forums for discussions to explore concerns.

33. ER nurses and paramedics should resolve differences without hard feelings occurring.

34. ER nurses and paramedics should feel safe to disagree with the opinions of each other.

35. ER nurses and paramedics should establish and maintain friendiy working relationships with each other.

38. There should be regular contact between ER nurses and paramedics through social functions.

\section{EACTOR III- EOUALITY OF INFLUENCE}

1. ER nurses and paramedics should have as much power as the other.

2. Suggestions of each person should be considered important.

3. Decisions on the patient's care should be made by both the ER nurse and paramedic.

4. Contributions of the ER nurse and the paramedic should carry equal weight. 
5. The ER nurse and paramedic should have a clear idea of what the other is doing most of the time.

6. There should be a high degree of participation between the ER nurse and paramedic.

7. The ER nurse and paramedic should be encouraged to have her/his say before patient care decisions are made.

8. ER nurses and paramedics should discuss important problens they are confronted with.

9. ER nurses and paramedics should ask for help and suggestions from each other.

37. Consultations should occur equally between ER nurses and paramedics on patient care concerns.

EACTOR IV-SHARED RESPONSIBIUITY AND ACCOUNTABILITY

26. ER nurses and paramedics should be accountable for quality patiemt care and patient satisfaction.

27. ER nurses and paramedics should be responsible for quality patient care and patient satisfaction. 
A five point likert scale was used to rate the "extent" of agreement for each statement where $1=$ strongly agree; 2 magree; 3 meutral; $4=$ disagree; and $5=$ strongly disagree. Likert scales are easily to understood by participants and easy to score. Reliability has been shown to increase as the scale is enlarged from two to five points. The is no statistical gain with greater than five points (Nunnally. 1978).

There are two parts to each statement. part A, addresses the question, "To what extent do you agree or disagree with the statement in regarding the item necessary to collaboration?". If you strongly agree that the statement is necessary for collaboration, you would put a circle around 1 or if you strongly disagree, you would circle 5

part B, address the question, "To what extent do you agree or disagree with the statement in regaras to how collaboration is practiced at present?". If you strongly disagree that the statement is the way collaboration is practiced at present, you would put a circle around 5 or if you strongly agree, you would circle 1 . A comment section was allotted after each statement to allow paxticipants to remark on individual components and to aderess any differences in their belief of what is necessary for collaboration verses what is practiced. 
Dart 3 consists of four free response questions that are open ended to allow the participants to express their overal or othex concerns regarding ER nursemparamedic relationship. The aspects being examined here include general perceptions of the nursemparamedic relationship. ways of improving collaboration and conflicts among nurses and paramedics.

Reliability of an instrument is the degree of consistency with which it measures the attribute it is suppose to be measuring (Polit \& Hungler, 1989). Conbach" coefficient alpha was used for the pen collaboration scale. The standardized item alpha for the nursing deans was .949 and 925 for the nursing administrators.

validity is the degree to which an instrument measures What it is suppose to be measuring (Polit \& Hungler, 1989). Pehl established both content validity and face validity by the tool being reviewed by four registered nurses who each had greater than 20 years in nursing education and nursing service administration.

Construct validity tests the extent to which the tool may be said to measure a theoretical construct or trait. This was completed through factor analysis. Factor analysis is a method for reducing a large number of variables into a smaller number called factors by discovering which ones "go togethex" and the relations between the clusters (polit * 
Hungler, 1989). Factor analysis demonstrated that forty-six of the fifty-two items had loadings of .40 or greatex. Four items loaded on more than one factor and the researcher placed the items within the most appropriate factor. Four of the six items that factored with loadings less than . 40 were retained because the items may be more appropriate for the clinical setting.

\section{Procedure}

The surveys were disbursed by the Principle Investigator to the ER Nurse Managers and the Fire Rescue special Assistant, who issued the surveys to the office in Charge of the rescue station. The Nurse Manager or officer in Charge then distributed the questionnaire to the participants in their institution (emergency room or rescue station). A cover letter explaining the purpose of the research, informed consent and instructions for completion along with a self addressed stamped envelope were attached to the survey.

The data collection was obtained for a one month period in December. Both nurse and paramedic participants were asked to return the survey prior to the end of the month. Follow-up consisted of contacting the nurse managers and the Fire Rescue Special Assistant as a remindex to encourage the ER nurses and paramedics to participate in the study. This 
was completed 14 days after the initial circulation of the questionnatres.

\section{Data Analysis}

The data analysis was done in 2 parts for the research question: What is the nature of the perception of collaborative relationship between emergency room nurses and the paramedics? simple statistics was used to examine the individual groups in regards to the demographic data and RPCS survey. The paramedics were compared to the ER nurses in order to answer the study question regarding personal attributes of age and gender, and social demographics of level of education and experience by the use of Pearson's Product Moment correlation. This type of analysis is seen with descriptive correlational research when comparing means of two groups. A significance level of $(p>0.05)$ was used as criteria for analysis.

For the second part, the free response questions, the data was analyzed by content analysis. content analysis is a procedure for analyzing written or verbal communication in a systematic and objective fashion (Polit \& Hungler, 1989). The goal of content analysis is to find relationships in the qualitative data that pertain to the research study. This is to answer the study question regarding areas of conflict between the ER nurses and paramedics. When the survey data 
were received, they were visually verified for completeness and then processed for computation. 


\section{Chaptex 4}

Results

Based upon all data collected from the ER nurses and paramedics, the following results are presented. These resulcs were analyzed using Lotus $1-2-3$ software by a personal statistician. They are presented in the following manner:

1. Demographic characteristics for the energency nurses and the paramedics were briefly summarized (Appendix E).

2. The research questions with their corresponding statistical information (Appendix G).

3. Content analysis of the free response questions.

Demographic characteristics

The subjects for the nurse group were comprised of 18 females $(81.8 \%)$ and 4 males $(18.2 \%)$ with a mean age of 37.6 years. The majority of the nurses, 11 (50.0항 were prepared in associate degree programs, $8(36.4 \%)$ in baccalaureate degree programs, $2(9.1 \%)$ in diploma programs ard $1(4.5 \%)$ in a masters degree programs as a nurse practitioner. The highest level of education received by the majority of the nurses $10(45.5 \%)$ was an associate degree in nursing, (18.2\%) with a baccalaureate degree in nursing, 3 (13.6\%) 
with a masters degree in nursing, 1 (4.5\%) with a diploma certificate, and $4(18.2 \%)$ with degrees other than nursing. The majority of the nurses reported their number of years from graduation as $6-11$ years $(N=6$ or $27.3 \%)$ and the number of years as an emergency nurse as $2-5(N=7$ or $31.8 \%)$ or $6-11$ years $(\mathrm{iv}=7$ or $31.8 \mathrm{8})$.

The subjects for the paramedic group were comprised of 22 males $(84.6 \%)$ and 4 females $(15.4 \%)$ with a mean age of 38.2 years. The majority of the paramedics, 15 (57.7잉 were prepared in certificate programs, and $10(38.5 \%)$ in associate degree programs. The highest level of education received by the majority of the paramedics 11 (42.3\%) was an associate degree and $10(38.5 \%)$ with a certificate, and 3 (11.5\%) with baccalaureate degree, The majority of the paramedics reported their number of years from graduation as 6-11 years ( $N=9$ or $34.6 \%$ ) and the number of years as a south Florida paramedic as $6-11$ years $(N=8$ or 30.8 \%) or $12-17$ years $(\mathrm{N}=8$ or $30.8 \%)$. Table $\mathrm{II}$ displays the demographic comparison betwen the emergency room nurses and paramedics. 
Table TI

COMPARISON OF DEMOGRAPHIC RESULTS

NURSES

PARAMEDICS

Mean Age

$$
37.7 \text { years }
$$

38.2 years

Gender

Female

$N=18,81.8 \%$

Male

$\mathrm{N}=4, \quad 18.2 \%$

$N=4, \quad 15,4 \%$

$N=22,84.6 \%$

Basic preparation

$\begin{array}{llr}\text { Diploma } & N=2, & 9.1 \% \\ \text { Associate } & \mathrm{N}=1, & 50.0 \% \\ \text { Bachelors } & \mathrm{N}=8, & 36.4 \% \\ \text { Masters } & \mathrm{N}=1, & 4.5 \%\end{array}$

$\mathrm{N}=15,57.7 \%$

$N=10,38,5 \%$

$N=0, \quad 0.0 \%$

$N=1, \quad 4.5 \%$

Highest degree

$\begin{array}{llr}\text { Diploma } & N=1, & 4.5 \% \\ \text { Associate } & N=11, & 50.0 \% \\ \text { Bachelors } & N=5, & 22.7 \% \\ \text { Masters } & N=5, & 22.7 \% \\ \text { PhD } & N=0 & 0.0 \% \\ \text { other } & N=0, \quad 0.0 \%\end{array}$

$N=10, \quad 38.5 \%$

$N=11,42.4 \%$

$\mathrm{N}=3, \quad 31.5 \%$

$N=1, \quad 3.8 \%$

$N=0, \quad 0.0 \%$

$N=1, \quad 3.8 \%$

Years since basic preparation

\begin{tabular}{|c|c|c|c|c|c|}
\hline $0-5 y$ & years & $N=4$, & $18.2 \%$ & $N=7$, & $26.9 \circ$ \\
\hline $6-11$ y & years & $N=6$, & $27.3 \%$ & $\mathrm{~N}=9$, & $34.6 \%$ \\
\hline $12-17$ & years & $N=7$, & $31.8 \%$ & $N=7$, & $26.9 \%$ \\
\hline $18-23$ & 3 years & $N=4$, & $18.2 \%$ & $N=3$, & $11.5 \%$ \\
\hline $24-29$ & 9 years & $\mathrm{N}=0$, & $0.0 \%$ & $N=0 ;$ & $0.0 \%$ \\
\hline $30-35$ & 5 years & $N=1$ & $4.5 \%$ & $N=0$, & $0.0 \%$ \\
\hline 36 or & r more & $N=0$, & $0.0 \%$ & $\mathrm{~N}=0$ & $0.0 \%$ \\
\hline
\end{tabular}

Years Emergency Nurse/County Paramedic

$\begin{array}{crrrr}0-1 \text { year } & N=0, & 0.0 \% & N=0, & 0.0 \% \\ 2-5 \text { years } & N=7, & 31.8 \% & N=8, & 30.5 \% \\ 6-11 \text { years } & N=7, & 31.8 \% & N=5, & 9.2 \% \\ 12-17 \text { years } & N=6, & 27.3 \% & N=8, & 30.8 \% \\ 18-23 \text { years } & N=1, & 4.5 \% & N=5, & 19.2 \% \\ 24 \text { or more } & N=1, & 4.5 \% & N=0, & 0.0 \%\end{array}$

The Research Questions

The following tables display corresponding statistical information related to the research questions in this study. 
Research question \#1: What effect does the personal attributes of age and gender have on the perceptions of the collaborative relationship between ER nurses and paramedics?

Research question $\# 2$ : What effect does the social demographics of experience and level of education have on the perceptions of the collaborative relationship between ER nurses and paramedics?

These research questions were analyzed by using Pearson's Product-Moment Correlations. Survey factors of age, education and experience were examined by individual. collaboration factors to determine significant correlations. Mean age, highest level of education and years as emergency nurses or county paramedic were used for the calculations.

There was no correlation between the personal attributes or social demographics for the nurses or paramedics except for the paramedics age and collaboration at present. There is minimal positive correlation because the null hypothesis was rejected because the $x=0.434$ and the critical $r=0.423$. The $\mathrm{P}$ value is between .050 and .020 . Even though this demonstrates statistical significance, the scatter diagram shows the points to be widely dispersed and of minimal value. Table III displays the results for the Pearson"s Product Moment for nurses and paramedics age, education, and level of education with the four collaboration factors and both parts $A$ and $B$ of the survey. 


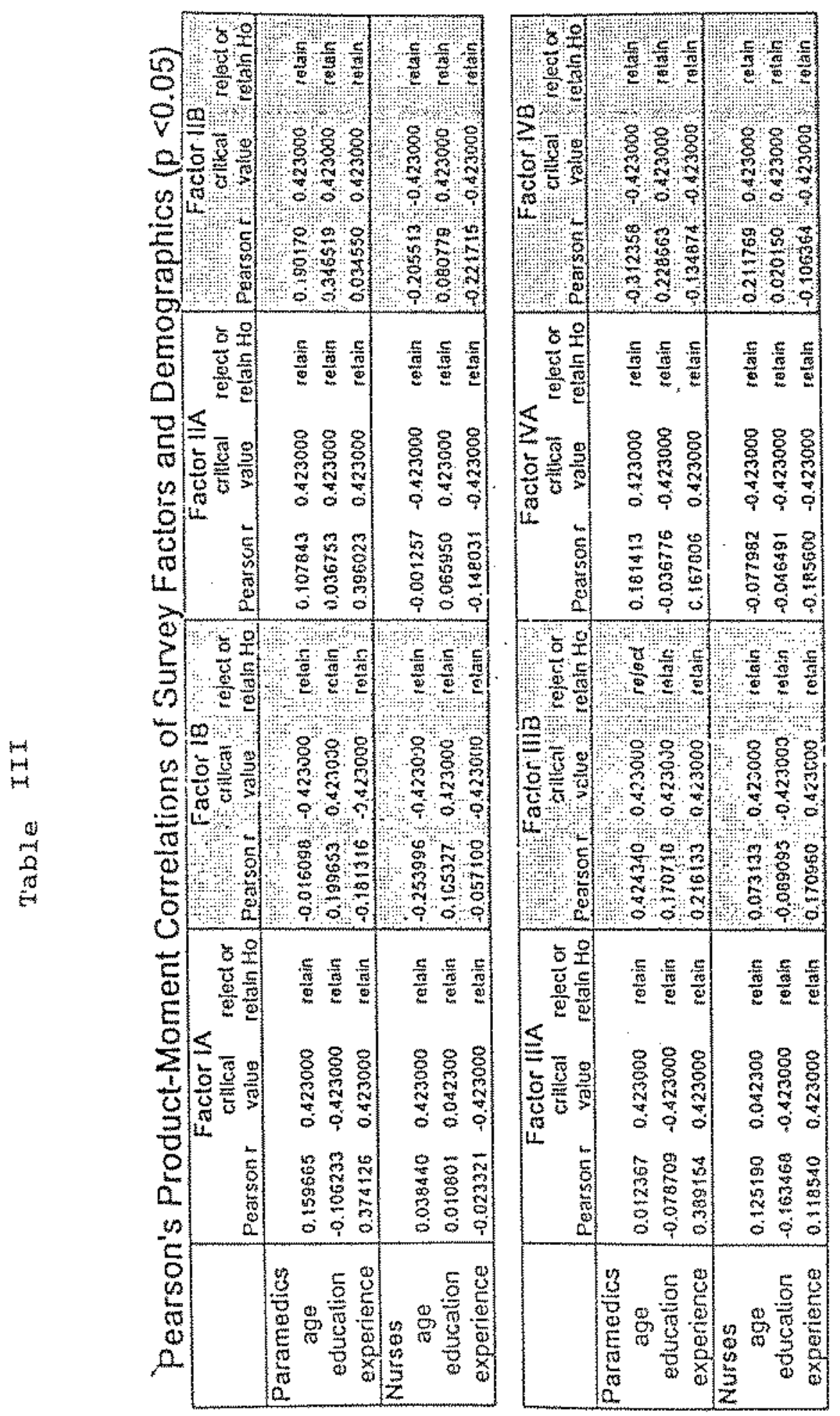

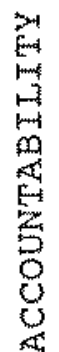

学

II $>-1$ Ex

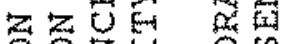

OO

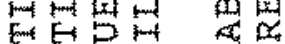

U 190

a on $\left[x_{3}\right.$ m

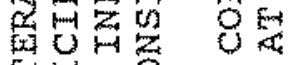

En 0

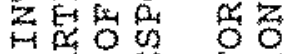

[x) 0 in

$P$ E

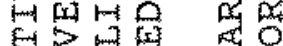

H 10 on

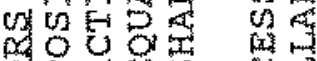

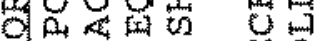

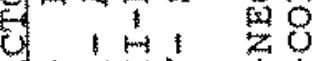

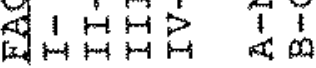


Research question \#3: What are the differences in the perceptions of the collaborative relationship between ER nurses and paramedics? scoxes for each question measuring perception were calculated in the following mannex: Each individual's response for a speciaic questions was added, arriving at a sum total score for each question. The mean or average response was obtained for each question by dividing the total score by the number of subjects. standard deviations were also calculated to determine the extent to which the mean was measuring the central tendency of the data for each question.

Table IV displays the perception results for the emergency nurses and the paramedics for both Parts $A$ and $B$ by Collaboration Factors. Appendix $\mathrm{H}$ displays the perception results by question for the emergency nurses and the paramedics for Part A (Necessary for Collaboration). Appendix I displays the perception results by question for the emergency nurses and the paramedics for Part B (Present Collaboration Practices). Appendix E contains the survey questions and percentages. 
FACTOR I- POSITIVE INTERACTION

\begin{tabular}{|c|c|c|c|c|}
\hline \multicolumn{3}{|c|}{ NURSES } & \multicolumn{2}{|c|}{ PARAMEDICS } \\
\hline Average & Mean & Std.Dev. & Mean & std.Dev. \\
\hline Part A & 2.149 & 1.177 & 3.000 & 1.1 .04 \\
\hline Part B & 3.050 & 1.241 & 3.305 & 1.117 \\
\hline
\end{tabular}

EACTOR II- ACIIVE PARTICIPATION

\begin{tabular}{|c|c|c|c|c|}
\hline \multirow[b]{2}{*}{ Average } & \multicolumn{2}{|l|}{ NURSES } & \multicolumn{2}{|c|}{ PARAMEDICS } \\
\hline & Mean & Sta.Dev. & Mean & std.Dev. \\
\hline Part $A$ & 1.788 & 1.228 & 1.922 & 1.123 \\
\hline Part $B$ & 2.660 & 1.199 & 2.942 & 1.046 \\
\hline \multicolumn{5}{|c|}{ EACTOR III- EOUALITY OF INELUENCE } \\
\hline \multicolumn{3}{|c|}{ NURSES } & \multicolumn{2}{|c|}{ PARAMEDICS } \\
\hline Average & Mean & Std.Dev. & Mean & sta. Dev. \\
\hline part A & 2.347 & 1.492 & 2.016 & 1.138 \\
\hline Part B & 2.931 & 1.195 & 3.063 & 1.067 \\
\hline \multicolumn{5}{|c|}{ EACTOR IV- SHARED RESPONSIBILITX AND ACCOUNTABILITX } \\
\hline \multicolumn{3}{|c|}{ NURSES } & \multicolumn{2}{|c|}{ PARAMEDTCS } \\
\hline Average & Mean & Sta. Dev. & Mean & Std. Dev. \\
\hline Part $\mathrm{A}$ & 1.364 & 0.932 & 1.846 & 1.026 \\
\hline Part B & 2.205 & 1.035 & 2.442 & 1.099 \\
\hline
\end{tabular}


A twomtailed tutest was used to examine the difference between means to compare the paramedic scores with the emergency nuxses. Both the nurses and paramedics strongly percieve that all factor are necessary for collaboration except for postive interaction $(p=0.0005)$. The paramedic donnot percieve postivie interaction as an important part of collaboration therefore the nul I hypothesis that there is no differnce in perception was rejected. Table $V$ aisplay results for the two-tailed t-test.

Table V

\begin{tabular}{|c|c|c|c|c|}
\hline \multicolumn{5}{|c|}{ 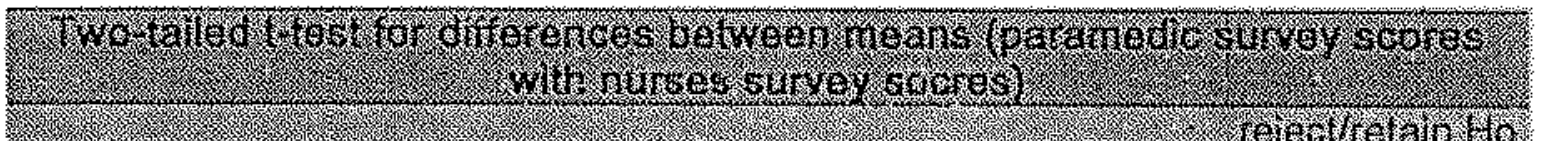 } \\
\hline & absened & leritharal & & $\begin{array}{r}\text { rejectretain Io } \\
\text { a } 000 \text {. }\end{array}$ \\
\hline Factor I-A & -3.485705 & -1.960000 & 0.0006 & reject \\
\hline Factor - B & 0.749020 & 1.98 & 86 & $\operatorname{ain}$ \\
\hline Iretor U A & 0.394654 & 1000000 & 19 & relan \\
\hline Fador II - 0 & 0.870384 & 1.060000 & 0. & retarn \\
\hline Faclor N. $N$ & 0.871228 & -1960000 & 0.38663 & $\tan$ \\
\hline Ractor W. D & 0.404236 & 1860000 & 0.68008 & ain \\
\hline factor IV - . & 1.690599 & 1,960000 & 0.0 & revalin \\
\hline $\operatorname{coc} v \operatorname{lv} \cdot \mathrm{g}$ & 0.764100 & 1.960000 & $0.44,61$ & retain \\
\hline
\end{tabular}

FACTORS

I- POSITIVE INTERACTION

TI- ACTIVE PARTICIPATTON

III-EQUAIITY OF INELUENCE

IV- SHARED RESPONSTBILITY AND ACCOUNTABTLITY

A-NECESSARY FOR COLUABORATION

B-COLLABORATION AT PRESENT 
Content Analysis

Research question \#4: What are the contextual factors in the collaborative relationship between ER nurses and paramedics? The final question, "Is there anything you would like to add?" was omitted because the comments made by the particlpants pertained to the pervious questions or to the structure of the survey such as "The wording of the study was awkward" or "I based the answers on field paramedics not hospital-based paramedics".

Question 1- How would you describe your relationship with the ER nurses/paramedics? Thoughts regarding the general relationship between the emergency nurses and the paramedics varied, but responses were generaliy positive. Many of the nurses responded that there was the "Mutual respect" among the nurses and paramedics and there was a "Professional working relationship". Others gave positive answers ranging from "Excellent", "Good", and "Friendly". Three of the nurses felt that the relationship "Depends on who the paramedics are" and that it was "Selective on the basis of pervious interactions and rapport of certain rescue stations. The better ones (stations) seem to interact better and make more sound patient decisions". Three other nurses indicated that there was "Too much socializing", "Very poor, either flirting or arguing" and that "The present enviromment does not allow for effective 
collaboration between the two groups".

The paramedic responses were not as positive as the nurses. Although some of the paramedics felt that there was a "strong working relationship", the majority of the comments indicated that the relationship "Varies tremendously from ER to ER". "Depends on the institution" or that "Some are better than the others especially when the paramedic and the nurses have been working togethex for awhile" were common remarks. One paramedic sumed up the relationship in one sentence: "They (nurses) are friendly but not fully trusting".

Question 2- What would you describe as common conflicts between the ER nurses/paramedics? The second free response question was directed toward common conflicts among nurses and paramedics. Both parties had similar statements regarding the areas of conflict. The nurses indicated that there were three major areas of conflict or stress. The majority identified that the patient report was the area that caused the most conflict. They felt that the. paramedics had "Inconsistencies in histories or care in the field" or that the "Radio report assessment was not complete or accurate" other responses recognized that "Final patient assessments differed from initial radio assessments" or that there were "Missed critical assessments". one nurse felt that "Poor assessment skills leads to a poor patient 
report"

The second area of confict was in regards to patient priorities. The level of facility the patient should be transported to or the level of transport (advanced cardiac life support, AcLs versus basic 1 ife support, BLS units) causes "Disagreement among the nurses and paramedics". The nurses felt that the "Skill levels" or "Focus of training" of the paramedics may contribute to their decision making ability.

The final identified area of conflict was concerning by-pass protocol. (By-pass is when a hospital emergency room notiries the EMS system that it is overcrowded and can not accept any more rescue patients at that time. Rescue units may bring a patient to a hospital on by-pass when the patient has an immediate life threatening condition, eg. cardiac arrest, or when all surrounding hospitals are also on by-pass.) statements like "The ED is too busy to accept all EMS patientsm we need to go on bypass frequentiy which irritates paramedics" and "Acceptance of patients, especially while on bypass" indicates a conflict. The nurses also felt that the "Paramedios don't understand the busy days in the $\mathrm{ER}^{\prime \prime}$ and that there is increased stress on the nursing staff when they are "The only hospital open". The paramedic responses were numerous but similar to the views shared by the FR rurses. The majority of the 
paramedics felts that "The nurses don't believe we know what we are doing" and that they received "Condewcending comments from nursing staff concerning patient care" one paramedic boldly stated, "whe feeling that many nurses have towards paramedics are that we are a substandard providers that are il.-trained and unqualified to administer patient care and that we don't have not enough knowledge ow business doing the things that we do in the field. Nurses have even commented that its obvious that the paramedics take a different ACLS course because ours is too hard for then" " The paramedics also identified conflict regarding decisions on patient care preformed on the streets. It was noted that there were differences between the nurses and the paramedics conceming the trauma critexia, the "Immediate necessity for patient care in high priority patients" or "In treatment of the patient, both care and quality". one paramedic expressed, "What is obvious in the ER may not be in the street and visa versa. The nurses think paramedics can't properly assess patient".

Another set of responses from the paramedics indicates that they have difficulties in being "heard" by the nurses when transferxing a patient from the rescue unit to the ER staff. "The nurses don't realiy listen to what we say in report" or they "Dismiss any data that we have reported to them". "We are often ignored wher we arwive at the ER desk 
with a patient" and the nurses "Think that we are on their turf when we drop patients of and that we should act accordingly"

Some paramedics think that conflict occurs because nurses are jealous of the role paramedics play in trauma and emergency cases. This jealousy is due to "Some nurses being resentful of the autonomy that the paramedics have in the field" and "That we can do things that they (nurses) can't and that only doctors are allowed to don" other paramedics "Resent an RN who attempts to direct medical care via telemetry rather than relaying information between the medic and the doctor". They felt that the nurses wanted total control of them.

Although the paramedics did not identify by-pass protocol as a source of conflict, they did note a conflict with the nursing staff over the delivery of additional patients to the emergency room. They felt that the "ER nurses may feel overworked and resent paramedics bringing them patients to take care of".

Question 3- How could the collaborative relationship between ER nurses/paramedics be improved? The responses from both groups will be examined jointly due to the overwhelming similarity in remarks.

The most frequent response for improving relations would be cross training. This took several different forms 
incluaing switching roles, role playing exercises, or work exchange programs by having $\mathrm{ER}$ nurses ride rescue and paramedics spend a day in the emergency room. one paramedic stated, "Time and expexience of each others job will increase oux understanding and ease most conflicts".

Another method of increasing collaboration would entail combining resources for formal joint educational programs, inservices, and professional meetings or events. Less formal ways of enhancing communication would be by providing a means of sharing of information such as newsletters, bulletin boards and luncheons for joint staff meetings. This would allow both groups to "Examine each others goals, follow up on certain cases and vexbalize any complaints". Both nurses and paramedics indicated the importance in setting the same standards for both to follow by encouraging similar ACLS/Trauma certifications, training together and joint education. Several persons noted the need to improve ER/EMS quality assurance. Follow-up on certain patient cases, contagious conditions eg. tuberculosis, ongoing audits, random chart review-looking at prehospital care versus hospital care and the disposition of the patient are techniques to assure optimal patient care.

Finally, education to improve communication anong nurses and paramedics. Improving the collaborative effort was stated by one paramedics as, "There is room for 
improvement and we need to come together to accomplish one common goal.. the best and most efficient patient care."

\section{Summary}

Three of the factors of collaboration, active participation, equality of influence, and shared accountability and responsibility were perceived as important components of collaboration by both the emergency nurses and paramedics. The factor of positive interaction was not perceived as an important component of collaboration by the paramedics as demonstrated by the t-utest for differences in the means. The quantitative data is supported by the content analysis due to the conflict noted by both the nurses and paramedics. The areas of conflict relate to interpersonal communication along with different occupational perspectives.

King's theory notes that communication is the key element in maintaining relationships. A persons" perceptions, values, needs, and educational background influences their interactions with the enviromment. When there are differences in perceptions, mutual goals cannot be obtained. Positive interaction is not viewed equally by the emergency roor nurses and paramedics which may accounted for the axeas of friction and conflict. 
The purpose of this study was to determine the nature of the perception of the collaborative relationship between emergency room nurses and paramedics. The sample for this study contained both nurses and paramedics. The results indicated that there was no statistical correlation between the emergency nurses and paramedics when examining personal attributes or social demographics.

The content analysis provided more significant results. The findings of the content analysis demonstrated that the relationship between emergency room nurses and paramedics is friendy but not fully trusting. The free response questions identified that the "report" of patient information from the paramedic to the ER staff was the origin the most conflict. The nurses felt that paramedic patient assessment, patient priorities, and by-pass protocol were problems. Whereas, the paramedics identified the nurses condescending manner and mistrust, not being "Iistened" to, and overcrowded emergency rooms as the source of their conflict. This is consistent with the finding by Palmer \& Gonsoulin (1992) who reported that open conflict between the nurse and paramedic are not frequent, but does occur. 
The report given by paramedics and the visual assessment of the patient by the nurse at the time of transfer seems to represent "flash points" of conflict. During these critical minutes when the paramedics and nurses should be devoting their efforts toward a common goal, they are most susceptible co hostile interactions. palmer and Gonsoulin (1992) associate the power struggles and "turf wars" to the educational goals and training which produces different occupational perspectives.

The level of education, focus of care (prehospital versus hospital), legal issues, and position of authority are the primary elements of conflict between emergency room nurses and paramedics. These components are similar the to conflict noted between nurses and physicians.

A barrier to communication is the educational gap between nurses and paramedics. This difference in education cause variations in the perceptions of each other and the world around them. As the level of education increases, the perspective of health care is examined from a higher capacity. Basic education of training level concentrates on the mechanics of preforming profession related tasks. As further knowledge is acquired, the profession expands conceptualiy and a new perspective develops.

Nurses and paramedics have diferent educational preparation. The educational structure for entry level 
nursing preparation is at the associate degree or

baccalaureate levels. The entry level paramedic training is at the certificate or associate degree levels. Fifty percent of the emergency nurses in this study, have an associate degree as the basic level of preparation and $57.7 \%$ of the paramedics have a certificate as their basic level of preparation.

Morgan and Mccann (1983) showed that the educational difference between nurses (who generally have undergraduate education) and physicians (who all have medical degrees) caused discord due to lack of communication, Iimited awareness of nursing roles and limited interactions with each other. Another researcher noted interactions between nurses and physician are generally positive but physician are more likely to interact with other physicians and nurses are more likely to interact with other nurses (Kerr, 1986). This communication pattern is noted with the emergency nurses and paramedics.

The focus of care between emergency nurses andparamedics is often a source of conflict. A study by Holkelman (1975) showed that physician and nurses place different values on specific areas of health care continum. The physician focuses on medicine of the treatment of diseases where the nurses focuses on patient care from a holistic approach, caring for all aspects of the patient. 
The values of the paramedic centers around the ability to quickly respond, provide immediate care, and safe transport to the hospital. The focus of each group is important to the care of the patient and makes each profession unique but can also create barriers to communication.

The hierarchial framework of health care requires that a single individual be ultimately responsible, legaliy and clinically to manage the patient's care. Physicians occupy that role which cause nurses to be viewed as physician extenders or helpers. Often emergency nurses feel that they are responsible for the patients care once the patient enters the hospital and may view the paramedics as the nurse's helper.

In the emergency room setting, the emergency room physician occupies the role of "the captain of the ship". The emergency room nurse often fills this position when the paramedics arrive because the physician is examining other patients. This framework of a single individual being responsible places strain on the transfer of power and authority from one person to another.

Power is the capacity to use resources in organizations to achieve goals (King, 1981). It is the ability to influence one or more persons to effect the outcome of a decision. Power is also a perception of control and authority. 
Women and men have frequently aiffered in their approaches to power. Men have been socialized to compete openly with one another for a goal whereas women have been socialized to cooperate and comply with group wishes (Reism Wieczorek, 1982). This socialization has occurred over a long period of time and is imbedded into societies values. Within the health care hierarchy, nuxses (primarily female) and physicians (primarjiy male) have been accustom to this socialization. Even as the nuxsing profession bands together for equality and empowerment, there axe still many physicians who view nursing as an extension of medicine (Morgan \& McCann, 1983).

The relationship between nurses and paramedics with regards to power socialization has been amiabie but has hidden friction. The nursing profession is established and views the paramedics as "the new kids on the block" with limited education and experience. The nurses, just as physicians did before them, views the newcomers, as extensions of nursing. On the other hand, the paramedics who are primarily male, view themselves as in control with power due to their socialization.

A study by Falbo (1982) examined the power strategies used by masculine, feminine, androgynous and undiffexentiated people in their intimate relationships. The power strategies varied along a drectness continum 
Which ranged from direct to indirect. The othex dimension indicated the extent to which the strategies involved unilateral or bilateral decision making. They identified 13 power strategies broken into 4 quadrants used in the relationships. They included: 1) Bilateral and Directtalking, reasoning, persistence, bargaining and persuasion; 2) Bilateral and Indirect-positive actions (smiling) and hinting; 3) Unilateral and Direct- asking, stating importance and telling; and 4) unilateral and Indirectnegative actions (pouting), withdrawal and laissez-faire. They concluded that bilateral and direct strategies were more commonly used by people who perceived themselves to have more power in their relationship while unilateral and indirect behaviors were used by people who perceived themselves as having less power. The typical strategies of the masculine and androgynous were direct and bijateral behaviors which are also typical of those with greater power. The strategies of the feminine and undifferentiated people were indirect and unilateral which are typical of persons with less power.

various behaviors both direct and indirect and bilateral and unilateral are used with interaction between the nurses and paramedics. The concept of the male-female relationship and power between emergency room nurses and 
paramedics should be considered an area for further research.

The level of education, focus of care, legal issues, male-female conflict and power are all concepts that influence decision-making processes. These perceptions are developed over time and determine our behaviors.

Attitudes and behaviors of individuals are affected by multiple of sources and unique pressures. However, it seems that there are structural features to the training received by nurses and paramedics that influence their interactions during the time of transfer. When the nurse and paramedics are on different tracks or wavelengths, and negative situations persist over time, relationships can degenerate to the point of harm for the patient.

In examining the $\mathrm{ER}$ nurse-paramedic relationship in relation to King's theory, it was noted that the concepts of authority, communication, decision-making, interaction, perception, power, roles, and transaction are the most applicable in this study with the collaborative process.

It was found that the power and authority of the paramedics stopped at the emergency room doors and the reign of power of the nurse started. Many of the paramedics and nurses felt that the other was overstepping the boundary when those guidelines were not followed. The paramedics resented when the nurses gave them orders of the radio 
Without first consulting the emergency physician and the nurses resented the paramedics taking control of patient care after report had been given to the nurse.

The element of interaction and transaction are connected by communication in a shared collaborative process. Within King's theory, the interaction phase where emergency room nurses and paramedics communicatate is marred. Each persons' perception varies due to differences in their educational backgrounds, skills, abilities and values. All these points are incorporated to the communication patterns of a person and influence theix responses to a situation.

If the interaction is positive, the nurses and paramedics feel a sense of camaraderie and the transaction is smooth. If the interaction is negative, the nurse or the paramedics may have interpreted the conflict as personal (individual paramedic with individual nurse), interpersonal (certain rescue station or shift with a certain hospital, or organizational (all paramedics with all ER nurses). This was demonstrated by the participants responses that the relationship "varied from emergency room to emergency room" or "depended on the rescue squad". The interactions also varied depending on the number of patients being treated in the emergency room, the acuity of the patient or activity (number of rescue calls) of the rescue squad. 
without $f$ irst consulting the emergency physician and the nurses resented the paramedics taking control of patient care after report had been given to the nurse.

The element of interaction and transaction are connected by communication in a shared collaborative process. Within King*s theory, the interaction phase where emergency room nurses and paramedics comunicatate is marred. Each persons' perception varies due to differences in their educational backgrounds, skills, abilities and values. All these points are incorporated to the communication patterns of a person and infiuence their responses to a situation.

If the interaction is positive, the nurses and paramedics feel a sense of camaraderie and the transaction is smooth. If the interaction is negative, the nurse or the paramedics may have interpreted the conflict as personal (individual paramedic with individual nurse), interpersonal (certain rescue station or shift with a certain hospital, or organizational (all paramedics with all ER nurses): This was demonstrated by the participants responses that the relationship "varied from emergency room to energency room" or "depended on the rescue squad". The interactions also varied depending on the number of patients being treated in the emergency room, the acuity of the patient ox activity (number of rescue calls) of the rescue squad. 
The results of the survey although not significant were encouraging and verified several of the assumptions. The majority of the participants responded favorably to the four components being necessary for collaboration. This supported the assumption that open communication, positive interaction, active participation, equality of influence, and shared responsibility and accountability are necessary for collaboration.

The second assumption which stated that open comunication is essential for the transfer of information and assists in maintaining the continuity and quality of care of the patient was sustained because the patient report was the most common area of conflict. This showed that without open communication that the procedure of exchanging information can result in conslict. Two of the other assumptions also pertain to this process by identifying that the individual's goals, needs, values influence the interaction (communication) process.

\section{Limitations of study}

The survey needed to be divided into separate questionnaires in order for the participants to stay focused on the topic of research. One survey to examine the factors for "necessary for collaboration" and the second to examine how "collaboration is at present. 
The survey design also did not allow for subtle changes in the degree of collaborative practice. The Likert scale needed to be change to a 7 mpint scale that answered the questions "to what extent is this concept necessary for collaboration" and "to what extent is this concept present in the way collaboration is practiced at present". This is necessary in order to ascertain the degrees of collaboration which might make the survey items significant.

Finally, by changing the structure of the survey into separate components, the tool could be evaluated for content validity. Comparing the results of the original between nursing deans and administrators to application in the clinical environment.

1. In spite of the efforts made, one of the limitations of the study was the low response rate, $22 \%$ on the part of the nurses and $28 \%$ on the part of the paramedic.

2. Further, following a review of the literature, there was limited availability of a tool that measures the perceptions of collaboration. Therefore, the researcher modified an existing scale that had been utilized once with nursing deans and nursing service administrators.

3. Subject selection was made by convenience sampling which is the weakest of methods. In addition, the surveys were distributed to the participants by persons other than the Principal Investigator. 
4. The survey instructions were not clear and may have contributed to many of the duplicate results.

5. The survey was unclear to a few of the emergency nurses to the type of paramedic being studied, fiela paramedics verses hospital-based paramedic.

6. Conducting a research study in the month of December may have distracted potential participants in completing and returning the survey.

7. A pilot study or a review of the survey from a formal expert panel may have reduced the number of limitations.

\section{Recommendations}

1. Replicating this study in anothex area representative of the general population, such as multiple counties, statewide or national, where there is a crosssection of both urban and rural paramedics.

2. Conducting a longitudinal type study where nurseparamedics interactions are examined over a period of a year.

3. Conducting further research on the male-female aspect of the professions in regards to power strategies. 4. Conducting a study that examines the disterences in behaviors with trauma verses nonmtrauma cases. 
5. Continue to validate the Revised Penl collaborative Practice scale, but with several revisions.

A. Changing the wikert response to reflect the degree of collaboration from greater to lesser for the examination of the "necessary for collaboration" component of the survey.

B. changing the inkert response to $1=a$ ways, $2=$ often, $3=$ sometimes, $4=$ seldom and $5=$ never for the "collaboration at present" component of the survey.

c. Separating the two components into individual survey to help decrease the confusion on which statement is being answered.

D. Clearly specify the participants to be included in the study, ie. field versus hospital based paramedics.

E. Pertorming a repeat factor analysis using clinical areas.

\section{Nursing Implications}

prehospital care is a rapidly expanding area of health care and is the gateway for many patients into the health care system especially with the use of "911" emergency system. This has helped in saving many lives that otherwise would have been lost. The elevated number of critically ill 
patients entering the emergency room has made communication between the nurses and paramedics even more important. Good communication and working relationships with paramedics contributes to nursing by providing a pleasant and trusting working environment. This benefits the patient by furnishing a smooth transfer from prehospltal to hospital care when the patient is unable to care for himself.

strong cooperation is necessary to provide quality patient care. This study has helped increase the awareness of collaboration and conflict in the present interactions of emergency nurses and paramedics. This increased perception will benefit the quality of patient care due to increased teamwork and a sense of continuity.

The study has also contributed to nursing by identifying factors of collaboration that can be addressed in nursing education when discussing the roles of other health care professionals. Closer collaborative practice between nursing education and other health care professionals is essential to give students, both nursing and paramedic, a prospective of the various roles within the health care system. Many suggestions, such as crossm training or joint education, have been identified by both nurses and paramedics improve the collaborative relationship. Incorporating these practices will enhance the developing the relationship and the future of 
prehospital care.

Research in the area of prehospital care and emergency nursing is crucial due to the increasing number of patients using the emergency medical system. The pximary benefit of this study to nuxsing research was expanding the knowledge regarding the interactions between ER nurses and paramedics. This study provided information on areas of confict in communication between ER nurses and paramedics which is crucial in promoting a collaborative relationship. It also furnishes methods of improving the relationship which may provide future opportunities for research.

There is a paucity in the literature in measuring the components of collaboration. This study used an undeveloped tool in a clinical setting with emergency nurses and paramedics to expand the use of the tool. Although the study was not statisticaliy significant, further research in the area of collaboration and developing tool to measure it's elements is important. Nursing research on the construct of collaboration is vital, not only within the health care system but to all working relationships.

Summary

Teamwork is the process by which a group of people work together towards a common goal (Tappen, 1983). It regules a degree of cooperation and communication with others. 
Although the results of this study indicated that patient report was the common area for conflict, it also identified means by which the collaborative practice could be improved. Cross-training, joint educational programs, informal staff meetings and social luncheons were manifested to enhance relations.

Patient perceptions of the emergency experience are formed during encounters with the emergency personnel, the hospital and the rescue system. Open commication between ER nurses and paramedics is essential for the transfer of information and assists in maintaining the continuity and quality of care of the patient. As stated by one paramedic, "There is room for improvement and we need to come together to accomplish one common goal.. the best and most efficient patient care." 
Beyer, J. E. (1981). Interpersonal communication as perceived by nurse educators in collegial interactions. Nursing Research, 30(2), $111-117$.

Beyer, J. E. \& Marshal1, J. (1981). The interpersonal dimension of collegiality. Nursing outlook, 29(11). $662-665$

Bracken, J. L. \& Dee, G. (1989). A systematic program designed to provide trauma patient follow-up to emergency nurses. Journat of Energency Nursing, 15(5), 410-413.

Bunting. S. M. (1988). The concept of perception in selected nursing theories. Nursing Science ouarterly, I(4), $168-174$.

Campbe11, J.M. \& Dowd, T. T. (1991). Promoting clinical research through collegial relationships. Nursing connections, $4(3), 39-45$.

Campbel1-Heider, N. \& Pollack, D. (1987). Barriers to physician-nurse collegiality: An anthropological perspective. Social science and Medicine, 25 (5), $421-425$.

Caroline, N. L. (1983). Emergency care in the stxeets (2nd ed.). Boston: Little, Brown and Company.

Carroll, P. F. (1987). Turf wars: Time for a truce? Nursing $87,(11), 43$.

Deutsch, M. (1949). A theory of cooperation and competition. Luman Relations, 2, 199-231.

Deutsch, M. (1973). The resolution of conflict. New Haven: Yale University Press.

Dick, M. J. (1986). Burnout in nurse faculty: Relationships with management style, collegial. support. and work load in collegiate programs. Journal of Professional Nursing, $2(4), 252-260$.

Eckert, C. (1971). Emergency room care. New Yoxk: Litule, Brown, pp. $1-3$.

Eubanks, P. (1991). Quaity improvement key to changing nurse-MD relations. Hospitals, Aprit $20,65,26-30$. 
Falbo, $\mathrm{T}$. (1982). PAQ types and power strategjes used in intimate relationships. Psychology of women quarterly. $6(4) ; 399-402$.

Grigsby, D. W. Mcknew, M. A. (1988). Work-stress burnout among paramedics. Psychological Reports, 63(1), 55-64.

Haber, J., Leach, A. M., Schudy, S. M. \& Sideleau, B. F. (1982). Comprehensive Psychiatric Nursing (2nd ed.). New York: MoGraw-Hill.

Hammond, L. K. \& Goldman, M. (1961). Competition and noncompetition and its relationship to individual and group productivity. Sociometry, 24, 46-60.

Hein, E. C. (1973). Communication in Nursing Dractice. pp. 221-223. Boston: Little, Brown and Company.

He11riegel, D. \& Slocum, J. W. (1974). Management: A Contingency Approach. New York: Addison-Wesley.

Hodes, J. R* \& Van Crombrugghe, P. (1990). Nurse-physician relationships. Nursing Management, 21(7), 73-75.

Homonoff, E. E. Maltz, P. F. (1991). Developing and maintaining a coordinated system of community-based services to chilaren. Community Mental Health Journal, $27(5), 347-358$.

Iles, P. A. \& Auluck, R. (1990). From organizational to interorganizational development in nursing practice: improving the effectiveness of interdisciplinary teamwork and interagency collaboration. Journal of Advanced Nursing, $15(1), 50 m 58$.

Jones, S. C. \& Vroom, V. H. (1964). Division of labor and performance under cooperative and competitive conditions. Journa 1 of Abnommal and Social Psychology, 68, 313-320.

Kalish, B. T. Kalish, P. A. (1977). An analysis of the sources of physician-nurse confilct. Journat of Nursing Administration, 7(1), 51-57.

Kasch, C. R. (1983). Interpersonal competence and communication in the delivery of nursing care. Advances in Nursing science, $17(1), 71-88$.

Kennedy, C.W. \& Garyin, B. J. (1988), Nurse-physician comunication. Applied Nursing Research, $1(3), 122-127$. 
Kennedy, R. H. (1966). Emergency caxe of the sick and injured: A manual for 1 aw enforcement, firefighters ambulance personnel, rescue squads and nurses.

(pp. $1-21 *$ ) Philadelphia: W.B. Saunders.

Kexr, I. C. (1986). Interpersonal distance of hospital staft. Western Journal of Nursing Research, 8(4), $350-364$.

King, I. M. (1992). King's theory of goal attainment. Nursing science Quatterly, 5(1), $19-26$.

King, I. M. (1986). Curriculum and Instruction in Nursing: concepts and Practice. Norwalk, cT: AppletonmCenturyCrofts.

king. I. M. (1981). A Theory for Nursing. New Yoxk: John wiley \& Sons.

King, I. M* (1971). Toward a Theory for Nursing. New York: John Wiley \& Sons.

Klein, J. (1956). The Study of Groups. London: Routledge.

Kolb, D. A., Rubin, I. M. McIntyre, J. M. (1974). organizational Psychology: An Experiential Approach. Englewood Cliffs, CA: Prentice-Hall.

Kraus, W. A. (1980). Collaboration in organizations. New York: Human Science Press.

LeRoux, R., Guetierrez, K. \& White, B. (1993). collaborative learning partnership creates the perinatal nurse practitioner. Nursing connections, 6(3), 65-70.

McMahon, R. (1990). Power and collegial relations among nurses on wards adopting primary nursing and hierarchical ward management structures. Journal of Advanced Nursing. $15(2), 232-239$

Mintz, A. (1951). Nonadaptive group behavior. The Journal of Abnomal and social Psychology, 46, 150-159.

Morgan, A. P. \& Mccann. T. (1983). Nurse-physician relationship: The ongoing conflict. Nursing Administration Quarterly, $6(2), 1-7$. 
Murphy, S. (1972), Emergency medical care: A right or a dream. In C.W. Sproul \& P.J. Mullanney (Ed.) Emergency Care assessment \& intervention (pp. 1-12). St.Louis: C.V. Mosby.

Myers, A. (1982). Team competition, success, and the adjustment of group members. Administrative Science Quarterty, $16(1), 31-78$.

Napier, R* \& Gershenfield, M. K. (1973). Groups: Theory and Expewisnce. Boston: Houghton Miflin.

Nolan, M. G. (1976). Wanted: Colleagueship in Nursing. Jouma1 of Nursing Administration, 6(2), 41-43.

Palmex, C. E. (1983). "Trauma Junkies" and streetwork. Urban Life, $12(2), 162-183$

Palmer, C. E. \& Gonsoulin, S. M. (1992). Nursemparamedic interactions: Teamwork or turf wars? Prehospital and Disaster Medicine, $7(1), 45-50$.

Palmer, C. E. \& Gonsoulin, S. M. (1990). Paramedics, protocols, and procedures: "Playing doc" as deviant role performance. Deviant Behavior, 11(2), 207-21.9.

Polit, D. F, \& Hungler, B. P. (1989). Nuxsing Research: Principles and Methods (4th ed.). New York: $3 . B$. Lippincott.

Prescott, P. A. \& Bowen, S. A. (1985). Physician-nurse relationship. Annals of Internal Medicine, $103(2)$, $127-133$.

Rahim, M* A. (1988). The development of a leader power inventory. Multivariate Behavioral Research, 23 (4), $491-503$.

Rahim, M. A. (1983). A measure of styles of handing confijct. Academy of Management Joumal, 26(2), 368-376.

Rahim, M. A. (1983). Measurement of organizational confilct. Journal of General Psychology, $109(3), 189-199$.

Rahim, M. A. \& Buntzman, G. F, (1988). Supervisory power bases, styles of handing conflict with subordinates and subordinate compliance and satisfaction. Journa of Psychology, $123(2), 195-210$. 
Reis-wieczorek, R. (1982). Rower Eolitics, and Policy in Nursing. New York: Springer. p.55.

Riehl-Sisca, J. (1989). Conceptual Models for Nursing Practice (3rd. ed.). Connecticut: Appleton. p.153.

Shah, H. S., Sullivan, D. T., Lattanzio, J. \& Bruttomesso, R. M. (1994). Prepaxing acute care nurse practitioners at the university of Connecticut. AACN-Clinical Issues in critical Care Nursing, $4(4), 625-629$.

Sieloff Evans, C. L. (1991). Imogene King: A Framework for Nursing. Newberry Park, CA.: Sage.

Stewart, c. (1990), Communication with Emergency Medical Service Providers. Emergency Medicine Clinics of North America, (1), 103-117.

Tappen, R. M. (1983). Nursing Leadership: Concepts and practice. Philadelphia: F. A. Davis.

Tay lor, J. C. \& Bowers, D. G. (1972). Survey of organizations. Ann Arbor: Institute for Social Research, University of Michigan.

Torgersen, K. A. \& Chamings, P. A. (1994). Examining collaborative relationships between anesthesiologist and certified registered nurse anesthetists in nurse anesthesia educational programs. AANA Journal, 62(2), $139-148$.

Waters, M. (1989). Collegiality, bureaucratization, and professionalism: A Weberian analysis. American Journal of Sociology, 24(5), 945-972.

Weiss, S. J. Davis, H. P. (1985). Validity and reliability of the collaborative practice scale. Nursing Research, 34(5), 299-305.

Willians, J., Baker, G., Clark, B., Ehnis-Roebuck, C., Gupta, L., Johnson, J., Nix. L. \& Petrillo, S. S. (1993). Collaborative preceptor training: A creative approach in tough times. Journal of Continuing Education in Nursing, $24(4), 153-157$.

Williams, M. (1985). The collegial relationship between social work and nursing. Journal of Professional Nursing. $1(6), 322,385$. 


\section{APRENDIX A}

\section{Florida International university School of Nursing}

Perceptions of collaboration between Emergency Room Nurses and Paramedics

Dear Participant:

You are invited to be a participant in the researoh project entitled Perceptions of Collaboration between Emeroency Roon Nurses and Paramedics, to be conducted at Florida International University during the rall semester, 1994 , with Linda S. Boylan, RN., as Principle Investigator. This project is to partially fulfill the requirements for a Masters of science in Nursing.

Your participation in completing this survey is very important. Approximately 60 emergency room nurses and 60 paramedics will be involved in the study. Information obtained will be kept confidential and results will be documented only as a group report. completing this survey will require approximately 30 minutes of your time. The survey will entail answering approximately 45 questions by placing a circle around the number that most appropriately responds to your perceptions.

There are no known risks or benefits involved and your. participation is purely voluntary. You may withoraw at any time, without any negative consequences. The survey should be completed by December 31,1994 .

By completing and returning the attached survey, you will be giving consent to participate in this research study. There are no fees to pay nor will any monetary compensation of any kind be provided.

If at any time you feel you want further information, please contact Linda Boylan, RN, Frincipal Investigator, at (305) 385-8471 and/or Dr. Donna Rush, Faculty Supervisor, Florida International University, school of Nursing, at (305) $940-$ 5971 .

once again, your assistance and cooperation is greatly appreciated.

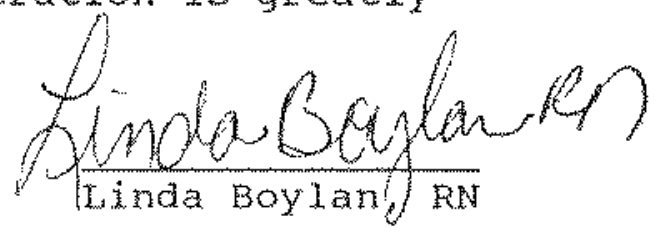


The following information will be helpful in analyzing differences which may exist in the perceptions of emergency room nurses and paramedics regarding collaboration. please consider each item and reply by circing the appropriate answer of filling in the blank.

A. Age to nearest birthday years.

B. Gender

1. Female

2. Male

c. BASIC level of nursing preparation

1. Diploma

2. ADN

3. BSN

4. Other, please specify

D. HIGHEST degree held

1. $\mathrm{ADN}$

2. BSN

3. MSN

4. PhD

5. Other, please specify

E. Years since graduation from basic nursing program

1. $0-5$ years

2. $6-11$ years

5. $24-29$ years

3. $12-17$ years

6. $30-35$ years

4. $18-23$ years

7. 36 or more years

F. Years as an Emergency Nurse
1. $0-1$ year
4. 12-17 years
2. 2-5 years
5. $18-23$ years
3. $6-11$ years
6. 24 or more years

G. Axe you licensed as a paramedic or emergency medical technician (EMT)?

1. no

2. yes, paramedic

3. yes, EMT 
The following information will be helpful in analyzing differences which may exist in the perceptions of emergency room nurses and paramedics regarding collaboration. please consider each item and reply by circling the appropriate answer of filling in the blank.

A. Age to nearest birthday. years.

B. Gender

1. Fenale

2. Male

C. BASIC level of paramedic preparation

1. Certificate

2. Associate degree

3. Bachelors degree

4. Other, please specify

D. HIGHEST degree held

1. Certificate

2. Associate

3. Bachelors

4. Masters

5. Other, please specify.

E. Years since graduation from basic paramedic program

1. $0-5$ years

2. 6-11 years

5. $24-29$ years

3. $12-17$ years

6. $30-35$ years

4. 18-23 years

7. 36 or more years

F. Years as a Metro-Dade Fire Rescue Paramedic

1. $0-1$ year

2. 2-5 years

4. 12-17 years

3. $6-11$ years

5. $18-23$ years

6. 24 or more years

G. Are you licensed as a nurse?

1. no

2. yes, registered nurse

3. Yes, licensed practical nurse (LPN) 


\section{APPENDIX C \\ REVISED PEHL COLLABORATION SCALE}

This instrument is a scale that examines collaborative practice between emergency room (ER) nurses and paramedics. The statements reflect behaviors in which collaboration may be described. After you read each statement carefully, circle the number which best indicates 1) your PERCEPTION of the extent that each statenent is necessary to collaboration between ER nurses and paramedics and 2) how you PERCEIVE the extent of how collaboration is practiced at present between the two groups. You may choose a response from one to five to describe your perception. If you think the statement is not appropriate to use in describing collaboration; circle "NA". The scale key is as follows:

$$
\begin{aligned}
& 1=\text { strongly agree } \\
& 2=\text { agree } \\
& 3=\text { neutral } \\
& 4=\text { isagree } \\
& 5=\text { strongly disagree } \\
& \text { NA=not appropriate }
\end{aligned}
$$

\section{Example:}

Part A: "To what extent do you agree or disagree with the statement in regarding the item necessary to collaboration?"

Part B: "To what extent do you agree or disagree with the statement in regards to how collaboration is practiced at present?"

ER nurses and paramedics almost always agree on patient care.
A. $12 \begin{array}{llllll} & 2 & 4 & 5 & \text { NA (Necessary to }\end{array}$

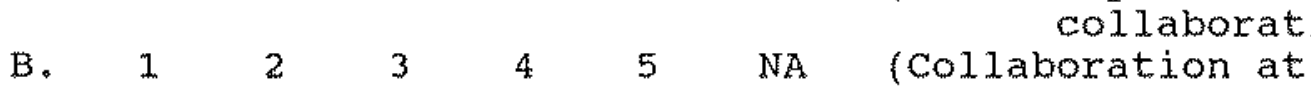
present)

Comments

A. If you strongly agree that the statement is necessary for collaboration, you would put a circle around 1 or if you strongly disagree, you would circle 5 .

B. If you strongly disagree that the statement is the way collaboration is practiced at present, you would put a circle around 5 or if you strongly agree, you would circle 1 . 
If you are an emergency room nurse completing this instrument, you should think in terms of the paramedics you work. With. If you are a paramedic completing this instrument, you should think in terms of the emergency nurses you work with.

\section{SCALE KEX}

$1=$ strongly agree

$2=\operatorname{agree}$

$3=$ neutra1.

$4=$ disagree

5 -strongly disagree

NAmnot appropriate

1. ER nurses and paramedics should have as much power as the other.
A. 1
3
45
$\mathrm{NA}$
(Necessary to
B. 1
2
3
4
5
NA Collaboxation at
collaboration)
present)

comments

2. Suggestions of each person should be considered important.
A. 1
2
3
45
$N A$
(Necessary to
B. 1
2
3
4
$5 \quad N A$
collaboration)
present)

Comments

3. Decisions on the patients" care should be made by both the ER nurse and paramedic.
A. 2
2
3
4
$5 \quad \mathrm{NA}$
(Necessary to
B. 1
2
3
45 NA
collaboration) present)

comments 
4. Contributions of the ER nurse and the paramedic should carry equal weight.
A. 1
23
4
5
NA
(Necessary to
collaboration)
B. 1
2

3
4
$5 \quad N A$
(Collaboration at
present)

Comments

5. The ER nurse and the paramedic should have a clear idea of what the other is doing most of the time.
A. 1
2
34
5
NA
(Necessary to
B. 1
2
3
4
$5 \quad N A$
collaboration)
present)

Comments

6. There should be a high degree of participation between the ER nurses and paramedics.
A. 1
2
34
5
NA
(Necessary to
B. 1212
$45 \quad \mathrm{NA}$
collaboration)
present)

Comments

7. The ER nurse and paramedic should be encouraged to have her/his say before patient care decisions are made.
3
4
$5 \quad \mathrm{NA}$
(Necessary to
B. 11203
$5 \quad \mathrm{NA}$
collaboration)
present)

Comments

8. ER nurses and paramedics should discuss important problems they are confronted with.
A.
2
4
$5 \quad \mathrm{NA}$
(Necessary to
B.

2
45
NA
collaboration present)

comments 
9. ER nurses and paramedics should ask for help and suggestions from each other.
A. 2
2
3
4
5
$\mathrm{NA}$
(Necessary to
collaboration)
B. 1

2

3
4.
5
NA
(Collaboration at present)

Comments

10. ER nurses and paramedics should work together as a team toward patient care goals.
A. 1
2
3
4
5
NA
(Necessary to
B. 1
2

3
4
5
NA
collaboration)
present)

Comments

11. Confidence and trust should exist between ER nurses and paramedics.
A. 1
23
4
5
NA
(Necessary to
B. 1.2
34
5
NA
collaboration) present)

Comments

12. $\mathrm{ER}$ nurses and paramedics should coordinate their efforts.
A. 1
3
4
5
NA (Necessary to
B. 1
2
34
$5 \quad \mathrm{NA}$
collaboration)
present)

Comments

13. ER nurses and paramedics should feel free to exchange ideas and opintons.
A.
2
3
45
NA
(Necessaxy to
B. 1
2
34
5 NA
collaboration)
present)

Comments 
14. ER nurses and paramedics should cooperate for achievement of patient care goals.
23
4
5
NA (Necessary to
B. 1
2
3
4
5
NA
collaboration) present)

Comments

15. ER nurses and paramedics should welcome information from each other.
A. 1
34
5
NA (Necessary to
collaboration)
B. 1
3

4
5
NA
collaboration at
present)

Comments

16. ER nurses and paramedics should be willing to share knowledge and lend assistance to each other.
A. 1
2
3
4
5
NA
(Necessary to
B. 1
2
3
4
5
NA
collaboration)
present)

Comments

17. ER nurses and paramedics should deal with conflict opendy.
A. 1
2
3
4
5
NA
(Necessary to
B. 12
$3 \quad 4 \quad 5$
NA
collaboration)
present)

Comments

18. ER nurses and paramedics should hold forums for discussions to explore concerns.
A. 1
2
34
$4 \quad 5 \quad \mathrm{NA}$
(Necessaxy to
B. 1
345
NA
collaboration)
present)

Comments 
19. ER nuxses and paramedics should share information about important events.
A. 1
2
3
45
NA
(Necessary to
B. 1
2
3
$4 \quad 5$
NA
collaboxation)
present)

Comments

20. ER nurses and paramedics should share continuing education programs and educational software.
A. 1
2
3
45
NA (Necessary to
B. 1
2
3
45
NA
collaboration) present)

Comments

21. ER nurses and paramedics should socialize new nurses/paramedics into the professional role.
A. 1
2
3
4
5
NA (Necessary to
B. 1
2
3
4
5
NA
collaboration)
present)

comments

22. ER nurses and paramedics should have an opportunity to experience each others professional role.
2
3
45
NA
(Necessary to
B. 12
34
45
NA
collaboration)
present)

Comments

23. ER nurses and paramedics should work together on joint research projects.
A.
2
34
$5 \quad$ NA
(Necessary to
B. 12
3
45
NA
collaboration)
present)

comments 
24. Provisions should be made for feedback of interagency information via newsletters, memos, or patient updates.
A. 3
23
4
5
NA
(Necessary to
B. 1
2

3
4
$5 \quad$ NA
collaboration)
present)

comments

25. The should be utilization of $E R$ nurses and paramedics as role models for nursing and paramedic students.
A.
2
3
4
5
NA
(Necessary to
B. 1
2

3
45
NA
collaboration)
present)

Comments

26. ER nurses and paramedics should be accountable for quality patient care and patient satisfaction.
A. 1
2
3
4
5
NA
(Necessary to
B. 1
2

3
45
NA
collaboration) present)

Comments

27. ER nurses and paramedics should be responsible for quality patient care and patient satisfaction.
A. 1
2
3
45
NA
(Necessary to
B. 1
2
3
4
5
NA
collaboration)
present)

comments

28. There should be a consensus between the professional. goals of ER nurses and paramedics.
2
3
4
$5 \quad \mathrm{NA}$
(Necessary to
B. 12
34
5
NA
collaboration)
present)

comments 
29. ER nurses and paramedics should participate in joint committees.
A. $\quad 1$
23
4
5
NA
(Necessary to
B. 12
34
5
NA
collaboration) present)

Comments

30. There should be cooperative orientation activities between new ER nurses and new paramedics.
A. 1
2
34
5
NA
(Necessary to
B. 1
2

3
4
$5 \quad \mathrm{NA}$
collaboration) present)

Comments.

31. ER nurses and paramedics should explore issues related to educational programs together.
A. 1
2
3
4
5
$N A$
(Necessary to
B. 1
2

3
4
5
NA
collaboration) present)

Comments

32. ER nurses and paramedjcs should explore patient care standards together.
A. 1
2
3
45
NA
(Necessary to
B. 12
34
$5 \quad N A$
collaboration)
present)

Comments

33. ER nurses and paramedics should resolve differences without hard reelings occuxring:
A. 1
2
3
4
5
NA
(Necessary to
B. 1
2
34
$5 \quad N A$
collaboration)
present)

coments 
34. ER nurses and paramedics should teel safe to disagree with the opinions of each othex.
A. $\quad$ i
3
4
5
NA
(Necessary to
B. 1
2
3
45
NA
collaboration)
present)

Comments

35. ER nurses and paramedics should establish and maintain friendly working relationships with each other.
2
3
4
5
NA
(Necessary to
B. 1
2
34
5
NA
collaboration)
present)

Comments

36. Strategic long-tern planning should be carried out between ER nurses and paramedics.
A. 1
34
5
NA
(Necessary to
B. 1
23
4
5
NA
collaboration) present)

comments

37. Consultations should occur equally between ER nurses and paramedics on patient care concerns.
A. 1
2
3
4
5
$\mathrm{NA}$
(Necessary to
B. 1
2
3
4

5
NA
collaboratjon)
present)

Comments

38. There should be regular contact between ER nurses and paramedics through social functions.
A. 1
2
3
4
5
NA
(Necessary to
B. 1

2
3

4
5
NA collaboration) present)

Comments 
APPENDIX D

Free Response Questions

1. How would you describe your relationship with the ER nurses/paramedics?

2. What would you describe as common conflicts between the ER nurses/paramedics?

3. How could the collaborative relationship between the ER nurses/paramedics be improved?

4. Is there anything you would like to add? 
Linda Boylan

13235-2 Southwest

Ootober 23,1994

H10 Terrace

Miani, Florida 33186

Deax Linda,

I enjoyed talking with you this evening regaxding your interest in collaboration between emergency roow nurses and paramedics. With the changes in our health care system, I think that the ability to collaborate effectively will be an essential skill required of all health caxe workers.

I think that the instrument that I developed for my aissertation, DEVELOPNENT OF AN INSTRUNENT TO MEASURE PERCEPTIONS OF COLIABORATTON EETWEEN NURSTIG DEANS AND NURSING SERVICE ADMTNTSTRATORS, will be helpful in your data collection process. I do give my permission for you to use my instrument in your research. The instrument is copyrighted so I know you will give proper credit.

When you complete your Thesis, I would like to have a copy of the abstract I am interested in seeing how others use the instrument in theix own research.

sincerely,

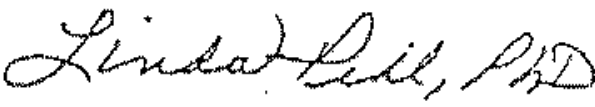

Linda penl, PhD

2208 University Dr.

Belton, $2 \times 76513$

(817) $939-3865$ (H) 


\section{APPENDIX F \\ EMERGENCY ROOM NUESES}

The following information will be helpful in analyzing differences which may exist in the perceptions of emergency room nurses and paxamedics regarding collaboration. please consider each item and reply by circling the appropriate answer of filling in the blank.

A. Age to nearest birthay $\operatorname{mean}=37.7$

B. Gendex
1. Female
$(N=18,81.8 \%)$
2. Male
$\left(\mathrm{N}=4, \quad 18.2 \frac{6}{4}\right)$

c. BASIC leve1 of nursing preparation

1. Diploma $(N=2,9.1 \%)$

2. ADN $(N=11,50.0 \%)$

3. BSN $\quad(N=8,36.4 \%)$

4. Other, please specify MSN ARNP $(N=1,4.5 \%)$

D. HTGHEST degree held

$\begin{array}{lll}\text { 1. } & \text { ADN } & (\mathrm{N}=10,45.5 \%) \\ \text { 2. } & \text { BSN } & (\mathrm{N}=4,1.8 .2 \%) \\ \text { 3. } & \mathrm{MSN} & (\mathrm{N}=3,13.6 \%) \\ \text { 4. } & \text { PhD } & (\mathrm{N}=0,0.0 \%)\end{array}$

5. Other, please specify Diploma $(N=1,4,5 \%)$,

MBA $\left(N=2,9,1 \frac{1}{2}, A D-P S y c h o l o g y(N=1,4,5 \%)\right.$. BSW $(N=1,4,5 \%$

E. Years since graduation from basic nursing program
1. $0-5$ years
$(\mathrm{N}=4,18.2 \%)$
5. $24-29$ years $(\mathrm{N}=0)$
2. $6-11$ years $(N=6,27,3 \%)$
6. $30-35$ years $(N=1,4.5 \%)$
3. $12-17$ years $(\mathrm{N}=7,31.8 \%)$
7. 36 or more $(\mathrm{N}=0)$
4. $18-23$ years $(\mathrm{N}-4,18.2 \%)$

F. Vears as an Emergency Nurse
1. $0-1$ year
$(\mathrm{N}=0)$
2. $2-5$ years
$(N=7,31.8 \%)$
4. $12-17$ yeaxs $(N=6,27.3 \%)$
3. 6-11 years
$(\mathrm{N}=7,31.8 \%)$
5. $18-23$ years $(\mathrm{N}=1,4.5 \%)$
6. 24 or more $(N=1,4.5 \%)$

G. Are you licensed as a paramedic or emergency medical technician (EMT)?

1. no

2. yes, paramedic

$$
(N=22,100.0 \%)
$$

Total Response-

Excluded Surveys incomplete form

ER nurse $0-1$ yr

both RN s medic

Total Included in Data Analysis

$$
\begin{array}{lr}
N=25, & 23.8 \% \\
N=2, & 1.98 \\
N=1, & 1.0 \% \\
N=0 & \\
N=22, & 21.0 \%
\end{array}
$$




\section{PARAMEDTCS}

The following information wil be helpful in analyzing diterences which may exist in the perceptions of emergency room nurses and paramedics regarding collaboration. please consider each item and reply by circling the appropriate answer of filling in the blank.

A. Age to nearest bixthday mean $=38.2$ years.

B. Gender

$\begin{array}{ll}\text { 1. Female }(N=4, & 15.4 \%) \\ \text { 2. Male } & (N=22,84.6 \%)\end{array}$

C. BASTC level of paramedic preparation
1. Certificate
$(N=15,57.7 \%)$
2. Associate degree $(\mathrm{N}=10 \quad 38.5 \%)$
3. Bachelors degree $(\mathrm{N}=0)$

4. other, please specify $(N=1,4,5 \%) \mathrm{MBA}$

D. HIGHEST degree held
1. Cextificate
2. Associate
$(\mathrm{N}=10,38.5 \%)$
3. Bachelors
$(N=11,42.3 \%)$
4. Masters
$(N=3, \quad 11.5 \%)$
5. Other, please specify Ed, $S,(N=1,3.8 \%)$
(N=1, $3.8 \%)$

E. Years since graduation from basic paramedic program
1. $0-5$ years $(N=7,26.9 \%) 5,24-29$ years $(N=0)$
2. 6-11 years $(N=9,34.6 \%) 6,30-35$ years $(N=0)$
3. $12-17$ years $(\mathrm{N}=7,26.9 \%) 7.36$ or more $(\mathrm{N}=0)$
4. $18-23$ years $(N=3,11.5 \%)$

F. Years as a Metro-Dade Fire Rescue Paramedic
1. $0-1$ year $(\mathrm{N}=0)$
4. $12-17$ years
$(N=8, \quad 30.8 \%)$
2. $2-5$ years $(\mathrm{N}=8,30.8 \%)$
5. $18-23$ years
$(N=5,19.2 \%)$
3. 6-11 years $(\mathrm{N}=5,19.2 \%) 6.24$ or more $(\mathrm{N}=0)$

G. Axe you 1 icensed as a nurse?
1. no
2. Yes, registered nurse
3. Yes, licensed practical nurse (LPN)

Total Response-

Excluded Surveys-incomplete form paramedic $0-1 y x$ both RN \& medic

Total Included in Data Analysis

$$
\begin{array}{lr}
N=30, & 30.0 \% \\
N=0 & \\
N=1, & 1.0 \% \\
N=2, & 2.0 \% \\
N=26, & 26.0 \%
\end{array}
$$


nim emergency nurses

$p=$ paramedics top number mumber of responses bottom number percent

1. ER nurses and paramedics should have as much power as the other.
A. $\frac{1}{4}$
$\frac{2}{1}$
$\frac{3}{1}$
4.5
18.2
7
4.5
p) $\begin{gathered}5 \\ 19.2\end{gathered}$
26.9
4
15.4
4
45.5
5
$N A$
22.7
7.9
1.
3.8
7.7
B. 1
n) 0
$\frac{2}{0}$
10
45.5
p) 1
3
11.5
8
$\frac{5}{5}$
4
NA
27.3
22.7
4.5
23,1
15.4
4
15. 4

2. Suggestions of each person should be considered important.
A. $\frac{1}{14}$
$\frac{2}{6}$
$\frac{3}{0}$
$\frac{4}{0}$
$\frac{5}{2}$
NA
63.6
$27 \cdot 3$
p) $\begin{gathered}1.8 \\ 69.2\end{gathered}$
4
0
2
15.4
7.7
9.1
$\mathrm{O}$
B. $\frac{1}{7}$
2
$\frac{3}{2}$
45.5
p) 3
9
9.1
9
$\frac{4}{2}$
9.1
34.6
4
15.4
1
3.8
3.8
34.6

$\begin{array}{cc}\frac{5}{1} & \mathrm{NA} \\ 4.5 & 0 \\ 0 & 1 \\ & 3.8\end{array}$


3. Decisions on the patients' care should be made by both the ER nurse and paramedic.
A. 1
n) 2
2
$\frac{3}{4}$
$\frac{4}{3}$
$\frac{5}{4}$
NA
9.1
p) $\quad 3$
40.9
18.2
13.6
18.2
6
23.1
5
3
3
11.5
11.5
6
23.1
B) $\frac{1}{1}$
4.5
2
27.3
$\frac{3}{5} \quad \frac{4}{7}$
22.7
$\frac{4}{7}$
5
19.2
31.8
$\frac{5}{3}$
13.6
p) 3.8
7.7
11.5
30.8
NA
0
6
$23 \cdot 1$

4. Contributions of the ER nurse and the paramedic should carry equal weight.
A. $\frac{1}{5}$
$\frac{2}{2}$
$\frac{3}{0}$
$\frac{4}{9}$
$\frac{5}{5}$
NA
22.7
$9 \cdot 1$
p) $\begin{gathered}9 \\ 34.6\end{gathered}$
8
30.8
4
40.9
15.4
3
11.5
22.7
0
1.
4.5
2
7.7

B. 1

n) 1

$\frac{2}{7} \quad \frac{3}{0}$

$\frac{3}{0} \quad \frac{4}{8}$

31.8

p) 1

6

7

23.1

26.9

36.4

7

26.9

$\frac{5}{4}$

NA

2

18.2

3

9.1

3.8

5. The ER nurse and the paramedic should have a clear idea of what the other is doing most of the time.
A. 1
n) 12
8
$\frac{3}{0}$
$\frac{4}{0}$
$\frac{5}{2}$
$\frac{\mathrm{NA}}{\mathrm{O}}$
54.5
36.4
p) $\begin{gathered}8 \\ 30.8\end{gathered}$
11
42.3
$\frac{3}{11.5}$
4
9.4
15.4
B.
n) 6

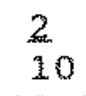
27.3
p) 2 7.7
45.5
$\frac{3}{1}$
4.5
11
42.3

$\frac{4}{3}$
13.6
5.
19.2
$\frac{5}{2}$
0
9.1
8
30.8
$\mathrm{NA}$
$\mathrm{O}$
0

2

7.7 
6. There should be a high degree of participation between the ER nurses and paramedics.
A. 1
n) 15
$\frac{2}{3} \quad \frac{3}{0}$
$\frac{4}{0} \quad \frac{4}{0}$
5
3
13.6
p) $\frac{12}{46.2}$
33.6
3
11.5
38.5
$\frac{1}{3.8}$
0
$\frac{N A}{O}$
B. $\frac{1}{3}$
11
$13 * 6$
50.0
p) $\quad \begin{aligned} & 1 \\ & 3.8\end{aligned}$
9
34.6
$\frac{3}{4} \quad \frac{4}{3}$
18.2
7
29.2
$\frac{4}{3}$
$\frac{5}{1}$
4.5
9
34.6
0
NA
0
0

7. The ER nurse and paramedic should be encouraged to have her/his say before patient care decisions are made.
A. $\frac{1}{7}$
$\frac{2}{7}$
$\frac{3}{3}$
$\frac{4}{2}$
$\frac{5}{3}$
NA
31.8
7
29.2
31.8
13.6
9.1
2
30.8
7.7
4
13.6
15.4
0
5
19.2
B. $\frac{1}{2}$
$\frac{2}{4} \quad \frac{3}{9}$
9.1
18.2
p) $\begin{gathered}1.1 \\ 3.8\end{gathered}$
7
26.9
$\frac{4}{4}$
40.9
6
18.2
$\frac{5}{3}$
NA
0
23.1
6
1.3.6
23,1
1
5
19.2

8. ER nurses and paramedics should discuss important problems they are confronted with.
A. 1 .
n) 13
2
$\frac{3}{3}$
$\frac{4}{0}$
$\frac{5}{2}$
NA
59.1
$18 \cdot 2$
13.6
9.1
p) $\begin{gathered}14 \\ 53 * 8\end{gathered}$
9
1.
2
7.7
0
0
3.8
4
18.2
31.8
$\frac{3}{6}$
$27 \cdot 3$
8
6
3.1
30.8
$\frac{N A}{O}$
34.6
2. 3.1
9.1
$\frac{5}{2}$
0
0 
9. ER nurses and paramedics should ask for help and suggestions from each othex.
A. $\frac{1}{11}$
p) $\begin{gathered}50.0 \\ 12 \\ 46.2\end{gathered}$
2
5
22.7
10
38.5
$\frac{3}{2}$
9.1
3
1.5
4
9.1
1.
3.8
$\frac{N B}{0}$
$\frac{5}{2}$
9.1
0
0
B. $\frac{1}{2}$
$\frac{2}{8}$
36.4
5
$\frac{3}{6}$
27.3
$\frac{4}{6}$
5
$\mathrm{NA}$
p) ${ }^{2} .7$
19.2
7
27.3
26.9
11
$42 \cdot 3$
1
3.8
0

10. ER nurses and paramedics should work together as a team toward patient care goals.
A. 1
n) 18
$\frac{2}{2}$
$\frac{3}{0}$
$\frac{4}{0}$
$\frac{5}{2}$
NA
81.8
9.1
p) $\frac{13}{50.0}$
8
30.8
1.
3.8
9.1
2
7.7
B. $\frac{1}{4}$
I. 18.2
2
10
$\frac{3}{5}$
45.5
22.7
9
34,6
6
23.1
2
7.7
0
7.7

$\frac{4}{4}$
18.2
7
5
NA
0
4.5
26.9
0

11. Confidence and trust should exist between ER nurses and paramedics.
A. 1
n) 17
$\frac{2}{3} \quad \frac{3}{0}$
$\frac{3}{0} \quad \frac{4}{0}$
$\frac{5}{2}$
NA
77.3
13.6
9.1
p) $\quad 18$
6
23.1
1
0
1
3.8
B. $\frac{1}{4}$
18.2
$\frac{2}{8}$
3.8
36.4
p) 1
9
34.6
$\frac{3}{1}$
4.5
5
19.2
8
36.4
$\frac{5}{1}$
4.5
10
1
38.5
3.8
$\frac{\mathrm{NA}}{0}$
0 
12. ER nurses and paramedics should coordinate theix efforts.
A. 1
n) 16
$\frac{2}{3}$
3
$\frac{4}{0}$
5
$9 \cdot 1$
p) 14
13.6
4.5
2
53.8
30.8
7.7
7.7
0
$\frac{\mathrm{NA}}{0}$
B . 1
n) 2
2
12
$\frac{3}{3}$
54.5
13.6
p) 1 10
11.
38.5
42.3

$\frac{4}{3}$
13.6
4
15.4
$\frac{5}{2}$
9.1
0
0
$\frac{N A}{0}$

13. ER nurses and paramedics should feel free to exchange ideas and opinions.
A. 1
n) 18
2
$\frac{3}{1}$
$\frac{4}{0}$
$\frac{5}{2}$
NA
p) $\quad 81.8$
4.5
4.5
1.
9.1
53.8
34.6
1
3.8
3.8
1
3.8
B. 1
n) 4
$\frac{2}{10} \quad \frac{3}{2}$
45.5
p) 3
7
26.9

$\frac{4}{3}$
13.6
8
30.8
$\frac{5}{3}$
NA
13.6
8
30.8
30.8

14. ER nurses and paramedics should cooperate for achievement of patient care goals.
A. 1
n) 18
$\frac{2}{2}$
$\frac{3}{0}$
$\frac{4}{0}$
$\frac{5}{2}$
NA
81.8
9.1
p) $\begin{gathered}1.3 \\ 50.0\end{gathered}$
9
34.6
1
0
9.1
3.8
2
7.7
B. 1
n) 5
$\frac{2}{8}$
$\frac{3}{3}$
36.4
13.6
p) 1
8
30.8
9
34.6

$\frac{4}{5}$
22.7
7.
26.9
$\frac{5}{1}$
4.5
0
1
3.8 
35. ER nurses and paramedics should welcome information from each other.
A. 1
n) $\frac{1}{16}$
2
3
$\frac{4}{0}$
5
2
NA
p) 13
13.6
4.5
50.0
10
1.
3.8
0
9.1
0
2
7.7

$\begin{array}{ccccccc}\text { B. } & 1 & 2 & 3 & 4 & 5 & \text { NA } \\ \text { n) } & 3 & 11 & \frac{3}{5} & 3 & \frac{5}{0} & 0 \\ & 1.3 .6 & 50.0 & 22.7 & 13.6 & & \\ \text { p) } 3 & 6 & 10 & 6 & 1 & 0 \\ & 11.5 & 23.1 & 38.5 & 23.1 & 3.8 & \end{array}$
0
$\frac{N A}{0}$

16. ER nurses and paramedics should be willing to share knowledge and lend assistance to each other.
A. 1
n) 17
$\frac{2}{3}$
$\frac{3}{0}$
$\frac{4}{0}$
$\frac{5}{2}$
NA
77.3
13.6
1
p) $\quad \begin{aligned} & 14 \\ & 53.8\end{aligned}$
30.8
2
3.8
9.1
7.7
1
3.8

B. 1

n) 5

2

22.7

10

45.5

$\frac{3}{1}$

4

5

NA

p) 3.5

5

19.2

4.5

27.3

10

7

0

0

1

26.9

3.8

17. ER nurses and paramedics should deal with conflict openly.
A. 1
n) 17
2
$\frac{3}{1}$
$\frac{4}{1}$
$\frac{5}{2}$
NA
77.3
4.5
4.5
$4 \cdot 5$
9.1
p) 10
6
4
3
15.4
1.. 5
3
1.1. 5
B) $\frac{1}{2}$
$23 \cdot 1$
$\frac{3}{5}$
22.7
p) 1
$\frac{2}{8}$
36.4
12
19.2
46.2

4
6
27.3
5
19.2
$\frac{5}{1}$
4.5
3.8
19.2
3
11.5
NA
0
0

19. 
18. ER nurses and paramedics should hold forums for discussions to explore concerns.
A. $\frac{1}{7}$
$\frac{3}{8}$
$\frac{3}{4}$
$\frac{4}{1}$
$\frac{5}{2}$
4. 5
9.1
p) $\begin{gathered}4 \\ 15.4\end{gathered}$
9
6
2
23.1
7.7
$\frac{3}{11.5}$
A
34.6
$\frac{3}{6}$
27.3
4
$\frac{5}{6}$
18.2
13.6
4
10
38.5
27.3
3.8
15.4

6
23.1
15.
NA
7.7

19. ER nurses and paramedics should share information about important events.
A. 1
n) 9
$\frac{2}{8}$
40.9
p) $\begin{gathered}6 \\ 23.1\end{gathered}$
36.4
$\frac{3}{2}$
9.1
16
1
3.8
$\frac{4}{1}$
4.5
$\frac{5}{2}$
9.1
61.5
1
3.8
1
3.8
1
3.8
NA
0

B. 1

ni 5

$\frac{2}{8} \quad \frac{3}{3}$

36.4

13.6

$\frac{4}{3}$

$\frac{5}{2}$

13.6

p) 1

6

10

5

9.1

1

19,2

3.8

38.5

3.8

20. ER nurses and paramedics should share continuing education programs and educational software.
A. $\frac{1}{7}$
$\frac{2}{7}$
$\frac{3}{4}$
$\frac{4}{2}$
$\frac{5}{2}$
NA
n) 7
31.8
18.2
p) $\begin{gathered}7 \\ 26.9\end{gathered}$
7
5
26.9
19.2
9.1
9.1
4
15.4
3.8
2
7.7
$\begin{array}{cc}\text { B. } & \frac{1}{2} \\ \text { p) } & 9.1\end{array}$
2
5
$22 * 7$
4
$\frac{3}{8}$
$\frac{4}{3}$
$\frac{5}{3}$
NA
36.4
15.4
4.
13.6
10
13.6
28.5
4
1
15.4
15.4
4.5
4
15.4 
21. ER nuxses and paramedios should socialize new nurses/paramedics into the professional role.
A. $\quad \frac{1}{9}$
n) 9
$\frac{2}{2}$
$\frac{3}{6}$
$\frac{4}{3}$
27.3
p) $\begin{gathered}10 \\ 38.5\end{gathered}$
9.1
7
13.6
26.9
15.4
$\frac{5}{1}$
$\mathrm{NA}$
1
3.8
$\frac{3}{12}$
4
54.5
13.6
18.2
5
6
19.2
23.1
4.5
0
4.5
4
15.4
B. $\frac{1}{1}$
11.5
7.7

$\frac{5}{1}$
4.5
4
15.4
NA
1
4.5
6
$23 \cdot 1$

22. ER nurses and paramedics should have an opportunity to experience each others professional role.
A. 1
2
$\frac{3}{3}$
$\frac{4}{1}$
$\frac{5}{2}$
4.5
9. 1
p) 10
36.4
13.6
47
26.9
3
11.5
2
$\frac{4}{0}$
$\frac{3}{3}$
13.6
31.8
8
3.8
30.8
6
$23 \cdot 1$
7.7
$\mathrm{NA}$
0
$\frac{5}{10}$
NA
0
10
45.5
3.8
9
34.6
1
3.8

23. ER nurses and paramedics should work together on joint research projects.
A. 1
n) 6
$\frac{2}{7}$
$\frac{3}{5}$
$\frac{4}{2}$
22.7
p) $\quad 5$
31.8
8
9.1
30.8
$\frac{5}{2}$
$\mathrm{NA}$
8
30.8
2
9.1
7.7
1
3.8
7.7
B. 1
n) 2
2
$\frac{3}{7}$
4.
31.8
4.5
p) 2
2
7.7
10
18.2
38.5
2
7.7

$\frac{5}{6}$
27.3
7
26.9
NA
2
9.1
3
1. . 5 
24. Provisions shoula be made for feedback of interagency information via newsletters, memos, or patient updates.
A. $\frac{1}{6}$
$\frac{2}{9}$
$\frac{3}{4}$
4
2
18.2
9.1
$\frac{5}{1}$
40.9
p) 76.9
12
2
3
4.5
46.2
$7 * 7$
11.5
1
3.8
Na
B. $\frac{1}{2}$
$\frac{2}{2}$
$\frac{3}{6}$
$\frac{4}{5}$
27.3
22.7
$\frac{5}{7}$
31.8
p) 2
$9 * 1$
5
8
6
19.2
30.8
23.1
I
3.8
11.5
$\frac{N A}{0}$
2
7.7

30.8

25. The should be utilization of $E R$ nurses and paramedics as role models for nursing and paramedic students.
A. 1
n) 10
$\frac{2}{7}$
$\frac{3}{2}$
$\frac{4}{1}$
9.1
4.5
p) 8
31.8
6
2
23.1
7.7
5
NA
30.8
23.1 4.5
1
3.8
3
11.5

3

13

59.1

3

4

B. 1

n) 4.5

4

13.6

13.6

15.4

6

6

p) $\begin{gathered}5 \\ 19.2\end{gathered}$

23.1

23.1

$\frac{5}{1}$

4.5

2

7.7

26. ER nurses and paramedics should be accountable for quality patient care and patient satisfaction.
A. 1
n) 18
$\frac{2}{2}$
$\frac{3}{1}$
$\frac{4}{0}$
5
NA
81.8
9.1
4.5
p) 13
9
2
7.7
1
34.6
3.8
4.5
1
3.8
B. 1
n) $\frac{1}{6}$
$\frac{2}{9}$
27.3
40.9
p) 5
10
$\frac{3}{3}$
4
$\frac{5}{0}$
NA
13.6
18.2
19.2
38.5
3
11.5
3
3.8

NA
1
4.5
3
11.5

11.5

$-\cdots$ 
30. There should be cooperative orientation activities between new ER nurses and new paramedics.
A. $\frac{1}{7}$
$\frac{2}{8}$
$\frac{3}{3}$
章
13.6
13.6
$\frac{5}{1}$
$\mathrm{NA}$
p) $\quad \frac{31.8}{6}$
36.4
9
34.6
2.
7.7
A. 5
23.1
$\frac{3}{6}$
4
27.3
7
$27 \cdot 3$
p) $\begin{gathered}1.8 \\ 3.8\end{gathered}$

2
6
27.3
2
7.7
26.9
13.6
8
30.8
0
3
11.5
5
NA
22.7
0
$15 \cdot 4$
4
15.4

31. ER nurses and paramedics should explore issues related to educational programs together.
A. 1
n) 6
2
$\frac{3}{4}$
$\frac{4}{2}$
18.2
36.4
p) $\begin{aligned} & 2 \\ & 7.7\end{aligned}$
7
6.9
10
9.1
B. 1
n) 1
$26.9 \quad 38.5$
4
$15 \cdot 4$
$\frac{5}{2}$
$\mathrm{NA}$
0
1
3.8
2
7.7
p) 2
$\frac{2}{6}$
27.3
1.
3.8

$\frac{3}{5}$
22.7
9
34.6
$\frac{4}{6}$
27.3
$\frac{5}{4}$
18.2
7
3
26.9
11. 5
NA
0
4
15.4

32. ER nurses and paramedics should explore patient care standards together.
A. $\frac{1}{7}$
$\frac{2}{7}$
$\frac{3}{6}$
31.8
p) 6
1.1
23.1
$42 \cdot 3$
27.3
5
19.2
4
4. 5
4
15.4
$\frac{\mathrm{NA}}{\mathrm{O}}$
$\frac{\frac{5}{1}}{4.5}$
0

B. $\frac{1}{2}$

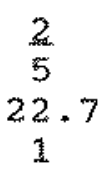

$\frac{3}{5}$

4.

22.7

$18 \cdot 2$

$\frac{5}{6}$

$N A$

13

6

27.3

3.8

50.0

23.1

15.4

1

3.8 
36. Strategic long-tern planning should be carried out between FR nurses and paramedics.
A. $\frac{1}{7}$
$\frac{2}{5}$
3
4
$\frac{5}{0}$
$\mathrm{MA}$
p) $\begin{gathered}31.8 \\ 3 \\ 11.5\end{gathered}$
22.7
27.3
18.2
9
23.1
34.6
3
11.5
0
5
19.2
B. $\frac{1}{2}$
2
3
68.2
$\frac{4}{3}$
13.6
5
$\frac{\mathrm{NA}}{\mathrm{O}}$
p) 1
3.8
2
7.7
6
7
23. 1
26.9
9.1
4
15.4
6
23.1

37. Consultations should occur equally between ER rurses and paramedics on patient care concerns.
A. $\quad 1$.
n) 8
2
$\frac{3}{2}$
36.4
9.1
p) 4
9
34.6
3
11.5
$\frac{4}{0}$
$\frac{5}{3}$
NA
13.6
5
19.2
0
1
4.5
5
19.2

B. 1

$\frac{2}{4}$

18.2

p) 2

3

11.5

$\frac{3}{9}$

40.9

3

11.5

4

3

$\frac{5}{5}$

NS

13.6

10

22.7

1

7.7

in. 5

38.5

3

11.5

4. 5

4

15.4

38. There should be regular contact between ER nurses and paramedics through social functions.
A. 1
n) 3
$\frac{2}{5}$
13.6
$22 \cdot 7$
p) $\begin{gathered}5 \\ 19.2\end{gathered}$
7
$\frac{3}{6}$
$\frac{4}{4}$
$\frac{5}{3}$
NA
27.3
8
18.2
3
13.6
1
26.9
30.8
11.5
4.5
3
1. 1.5
$\begin{array}{cc}\text { B. } & 1 \\ \text { n) } & 1 \\ \text { p) } & 4.5\end{array}$
$\frac{2}{2}$
9.1
4
$\frac{3}{7}$
31.8
14
53.8
$\frac{4}{7}$
5.
31.8
15.4
19.2
$\frac{5}{4}$
18.2
1
3.8
$\mathrm{NA}$
1
4.5
2
7.7 


\section{APPENDIX}

PERCEPTIONS OF PRESENT COLLABORATION PRACTTCES

\section{NURSES}

\begin{tabular}{|c|c|c|c|}
\hline No. & $\mathbb{N}$ & Mean & Sta.dev. \\
\hline Ib. & 20 & 3.952 & 0.722 \\
\hline $2 \mathrm{~b}$. & 21 & 2.091 & 1.083 \\
\hline $3 \mathrm{~b}$. & 21 & 3.227 & 1.125 \\
\hline $4 \mathrm{~b}$ & 19 & 3.350 & 1.276 \\
\hline $5 \mathrm{~b}$. & 21 & 2.318 & 1.257 \\
\hline $6 b$. & 21 & 2.455 & 1.033 \\
\hline $7 \mathrm{~b}$ & 21 & 3.091 & 1.124 \\
\hline $8 \mathrm{~b}$. & 21 & 2.773 & 1.165 \\
\hline $9 \mathrm{~b}$. & 21 & 2.727 & 0.962 \\
\hline $10 \mathrm{~b}$ & 21 & 2.500 & 1.118 \\
\hline $11 \mathrm{~b}$ & 21 & 2.272 & 1.250 \\
\hline $12 \mathrm{~b}$. & 21 & 2.591 & 1.114 \\
\hline $33 \mathrm{~b}$ & 21 & 2.591 & 1.302 \\
\hline $14 \mathrm{~b}$ & 21 & 2.500 & 1.197 \\
\hline $15 \mathrm{~b}$ & 21 & 2.364 & 0.881 \\
\hline $16 \mathrm{~b}$ & 21 & 2.364 & 1.110 \\
\hline $17 \mathrm{~b}$ & 21 & 2.818 & 1.072 \\
\hline $18 \mathrm{~b}$ & 21 & 3.318 & 1.361 \\
\hline $19 \mathrm{~b}$ & 20 & 2.476 & 1.258 \\
\hline $20 b$ & 21 & 2.318 & 1.257 \\
\hline $21 b$. & 20 & 2.286 & 1. 278 \\
\hline $22 \mathrm{~b}$ & 21 & 3.409 & 1.527 \\
\hline $23 b$. & 19 & 3.550 & 1. 244 \\
\hline $24 \mathrm{~b}$ & 21 & 3.591 & t. 267 \\
\hline $25 \mathrm{~b}$ & 20 & 2.524 & 0.957 \\
\hline $26 \mathrm{~b}$. & 21 & 2.227 & 1.041 \\
\hline $27 \mathrm{~b}$ & 21 & 2.182 & 1.029 \\
\hline $28 b$ & 20 & 2.952 & 1.133 \\
\hline $29 b$. & 21 & 2.955 & 0.976 \\
\hline $30 \mathrm{o}$ & 21 & 3.136 & 1.290 \\
\hline $31 \mathrm{~b}$ & 21 & 31.73 & 1.175 \\
\hline $32 \mathrm{~b}$. & 21 & 3.318 & 1.328 \\
\hline $33 \mathrm{~b}$ & 21 & 2.864 & 1.254 \\
\hline $34 \mathrm{~b}$. & 21 & 2.455 & 1.269 \\
\hline 350 & 21 & 2.000 & 1.128 \\
\hline 360 & 21 & 3.136 & 0.919 \\
\hline $37 \mathrm{o}$ & 20 & 3.429 & 1.050 \\
\hline $38 \mathrm{~b} *$ & 20 & 3.524 & 1.052 \\
\hline
\end{tabular}

PARAMEDICS

\begin{tabular}{|c|c|c|}
\hline N & Mean & Sta. Dev. \\
\hline 22 & 3.500 & 1.077 \\
\hline 25 & $2 \cdot 560$ & 0.898 \\
\hline 20 & 3.700 & 1.269 \\
\hline 24 & 3.208 & 1.079 \\
\hline 26 & 2.731 & 0.857 \\
\hline 26 & 2.923 & 0.917 \\
\hline 21 & 2.952 & 0.999 \\
\hline 26 & 2.731 & 1.021 \\
\hline 26 & 3.154 & 1.026 \\
\hline 26 & 2.731 & 0.943 \\
\hline 26 & 3.038 & 1.018 \\
\hline 26 & 2.692 & 0.773 \\
\hline 26 & 2.802 & 1.001 \\
\hline 26 & 2.962 & 0.940 \\
\hline 26 & 2.840 & 1.026 \\
\hline 25 & 2.840 & 0.967 \\
\hline 26 & 3.154 & 1.013 \\
\hline 23 & 3.864 & 1.013 \\
\hline 23 & 2.957 & 0.908 \\
\hline 24 & 2.375 & 1.184 \\
\hline 22 & 2.227 & 1.203 \\
\hline 25 & 3.840 & 1.081 \\
\hline 23 & 3.435 & 1.245 \\
\hline 24 & 3.542 & 1.224 \\
\hline 23 & 2.826 & 1.274 \\
\hline 26 & 2.423 & 1.044 \\
\hline 26 & 2.462 & 1.151 \\
\hline 24 & 3.167 & 0.898 \\
\hline 22 & 3.636 & 1.150 \\
\hline 22 & 3.455 & 0.988 \\
\hline 22 & 3.364 & 1.068 \\
\hline 25 & 3.440 & 0.941 \\
\hline 24 & 3.125 & 1.201 \\
\hline 25 & 2.760 & 1.242 \\
\hline 2.5 & 2.360 & 0.843 \\
\hline 20 & 3.550 & 1.071 \\
\hline 21 & 3.429 & 1.178 \\
\hline 24 & 3.167 & 0.799 \\
\hline
\end{tabular}




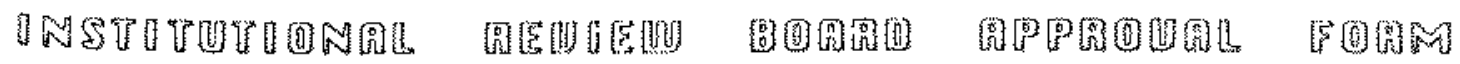

\section{FLUIIDN INTERNDTIONDL UNIUERSITE \\ University Park Campus \\ Miami, Forida 33199}

This is to certify that the program listed below has been reviewed and approved/denied by the Instiqutional Review Board (180) in accordance with the requirements of 45 CFn 46 , including its releuant subparts.

Principal Investigator/project Directar: Linda Boylan

Title of Application: Pexceptions of Collaboration Between Energency Room Nurses and Paramedics.

Agency submitted to:

Proposal Identification Number (if available):

\section{Certificare of InB:}

Date of the theuieu and Rpproval/Denial

$\checkmark$ Full Board Bavieu Experited Review

Comments: - Study was anotowed pondimg the fullowing changen.

1. Please provide information on consent form as to approximate number subjects in the study.

Any problems should bo immediataly brought to the attention of the Inb Councll

The official signing below certifies that the information on this form is carrect and the Institution assumes responsiblity for assuring future revious, approtals and submissigns of certification.

Kat Es Kroeck, Chalporson,

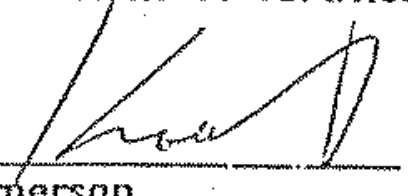

lind commitee 
27. ER nurses and paramedics should be responsible for quality patient care and patient satisfaction.
A. 1
n) 18
2
$\frac{3}{1}$
$\frac{4}{0}$
$\frac{5}{1}$
4.5
p) 11
$9+1$
4
34.6
15.4
1
4.5
42.3
7
31.8
3
3.8
1
3.8
NB
B. 1
n) $\frac{7}{31.8}$
8
22.7
$\frac{4}{3}$
13.6
p) $\quad 6.1$
30.8
8
2
30.8
7.7
$\frac{5}{0}$
2
7.7

28. There should be a consensus between the professional goals of ER nurses and paramedics.
A. $\frac{1}{3}$
$\frac{2}{7}$
$\frac{3}{7}$
$\frac{4}{3}$
$\frac{5}{3}$
NA
1.3 .6
31.8
31.8
p) 7

4
10
13.6
15.4
38.5
2
4.5
1
1
26.9
3. 8
4.5
7.7
2
7.7

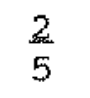

$\frac{3}{9}$

$\frac{4}{2}$

B. 1

n) 2

p) 1

22.7

3.8

4

40.9

10

1.5. 4

38.5

9.1

8

30.8

$\frac{5}{3}$

13.6

1

3.8

NA

1

4.5

2

7.7

29. ER nurses and paramedics should participate in joint committees.
A. 1
n) 6
$\frac{2}{9}$
$\frac{3}{5}$
$\frac{4}{1}$
22.7
4.5
$\frac{5}{1}$
NA
27.3
40.9
6
3
4.5
p) 6 .
30.8
23.1
11.5
1
3.8
2
7.7
B. 1
n) 1
$\frac{2}{6}$
p) 1
27.3
2
$\frac{3}{10}$
4
$\frac{5}{2}$
NA
45.5
13.6
8
4.
9.1
7.7
30.8
1.5. 4
7
26.9 
APPENDIX H

PERCEPTIONS NECESSARY FOR COLIAEORATION

\begin{tabular}{|c|c|c|c|c|c|c|}
\hline \multirow[b]{2}{*}{ No. } & \multirow[b]{2}{*}{$\mathbb{N}$} & \multicolumn{2}{|l|}{ NURSES } & \multirow[b]{2}{*}{$\mathrm{N}$} & \multicolumn{2}{|c|}{ PARAMEDTCS } \\
\hline & & Mean & Sta.Dev. & & Mean & Sta.Dev. \\
\hline 12. & 21 & 3.773 & 1.312 & 24 & 2.657 & 1.213 \\
\hline $2 a$ & 21 & 1.636 & 1.150 & 25 & 1.440 & 0.983 \\
\hline $3 a$. & 21 & 2.909 & 1.276 & 20 & 2.850 & 1.276 \\
\hline $4 a$. & 20 & 3.333 & 1.522 & 24 & 2.167 & 1.067 \\
\hline $5 a$ & 21 & 1.727 & 1.135 & 26 & 2.115 & 1.012 \\
\hline $6 a$. & 21 & 1.818 & 1.435 & 26 & 1.692 & 0.067 \\
\hline $7 a$. & 21 & 2.409 & 1.370 & 21 & 2.143 & 1.082 \\
\hline $8 a$. & 21 & 1.818 & 1.230 & 26 & 1.654 & 0.875 \\
\hline $9 a$. & 21 & 2.045 & 1.331 & 26 & 1.731 & 0.811 \\
\hline $10 a$ & 21 & 1.455 & 1.157 & 26 & 1.923 & 1.238 \\
\hline $11 a$. & 21 & 1.500 & 1.158 & 26 & 1.462 & 0.887 \\
\hline $12 \mathrm{a}$ & 21 & 1.591 & 1.193 & 26 & 1.692 & 0.910 \\
\hline $13 \mathrm{a}$. & 21 & 1.500 & 1.197 & 26 & 1.692 & 0.991 \\
\hline $14 \mathrm{a}$. & 21 & 1.455 & 1.157 & 26 & 1.846 & 1.167 \\
\hline $15 \mathrm{a}$. & 21 & 1.591 & 1.193 & 26 & 1.769 & 1.085 \\
\hline $16 a$. & 21 & 1.500 & 1.158 & 26 & 1.731 & 1.021 \\
\hline $17 a$. & 21 & 1.636 & 1.298 & 26 & 2.345 & 1.385 \\
\hline $18 \mathrm{a}$. & 21 & 2.227 & 1.203 & 24 & 2.652 & 1.218 \\
\hline 19 a. & 21 & 2.045 & 1.224 & 25 & 2.000 & 0.894 \\
\hline $20 \mathrm{a}$. & 21 & 2.318 & 1.257 & 24 & 2.375 & 1.184 \\
\hline $21 \mathrm{a}$. & 20 & 2.286 & 1.278 & 22 & 2.227 & 1.203 \\
\hline $22 \mathrm{a}$. & 21 & 2.136 & 1.217 & 26 & 2.346 & 1.299 \\
\hline $23 \mathrm{a}$ & 21 & 2.409 & 1.231 & 24 & $2 \cdot 417$ & 1.037 \\
\hline $24 a$. & 21 & 2.227 & 1.084 & 25 & 2.160 & 1.084 \\
\hline $25 a$. & 21 & 1.955 & 1.147 & 23 & 2.217 & 1.140 \\
\hline $26 a$. & 21 & 1.364 & 0.932 & 26 & 1.769 & 1.012 \\
\hline $27 a$. & 21 & 1.364 & 0.932 & 26 & 1.923 & 1.035 \\
\hline $28 a$ & 20 & 2.619 & 1.045 & 24 & 2.417 & 1.115 \\
\hline $29 a$. & 21 & 2.182 & 1.029 & 24 & 2.375 & 1.11 1 \\
\hline 30 a. & 21 & 2.227 & 1.165 & 23 & 2.304 & 0.953 \\
\hline $31 \mathrm{a}$. & 21 & 2.364 & 1.226 & 24 & 2.792 & 0.957 \\
\hline $32 a$. & 21 & 2.182 & 1.072 & 26 & 2.269 & 0.953 \\
\hline $33 a$. & 21 & 1.909 & 1.240 & 26 & 1.692 & 0.991 \\
\hline 34. & 21 & 1.818 & $1+154$ & 26 & 1.692 & 0.821 \\
\hline 352. & 23 & 1.591 & 1.193 & 26 & 1.538 & 0.843 \\
\hline $36 a$. & 21 & 2.318 & 1.1 .03 & 21 & 2.571 & 0.904 \\
\hline $37 a$. & 20 & 2.045 & 1.364 & 22 & 1.962 & 1.344 \\
\hline $38 a$. & 20 & 2.952 & 1.253 & 23 & 2.391 & 0.966 \\
\hline
\end{tabular}


33. ER nurses and paxamedics should xesolve differences without hard feelings occurring.
A. 1
n) 11
$\frac{2}{7}$
$\frac{3}{1}$
4.
4.5
31.8
1
4.5
$\frac{5}{2}$
9.1
p) 14
9
3.8
1
3.8
1.
3.8
$\frac{N A}{0}$
0
B) $\frac{1}{2}$
$\frac{2}{9} \quad \frac{3}{5}$
4
9. 1
$40.9 \quad 22.7$
p) 13
4
7
7
26.9
26.9
$\frac{5}{4}$
18.2
15.4
3
1.1. 5
$\frac{N A}{O}$
2
7.7

34. ER nurses and paramedics should feel sare to disagree with the opinions of each other.
A. 1
n) 11
$\frac{2}{8}$
$\frac{3}{1}$
$\frac{4}{0}$
$\frac{5}{2}$
9.1
p) 13.0
36.4
4.5
93
1
11.5
3.8
0
$\frac{N A}{0}$
34.6
4
3
4.5
4
18.2
$\frac{5}{2}$
9.1
p) 5
45.5
3
9
1
34.6
3.8
0
i. 1.5
$\frac{N A}{0}$
1 3.8

35. ER nurses and paramedics should establish and maintain friendly working relationships with each other.
A. 1
n) 16
$\frac{2}{3}$
$\frac{3}{1}$
$\frac{1}{0}$
$\frac{5}{2}$
4.5
9. 1
p) 16
13.6
0
$7^{2}$
0
$\mathrm{NA}$
0
30.8
7.7
9
34.6
B. 1
n) 9
$\frac{2}{8} \quad \frac{3}{2}$
$\frac{4}{2}$
9.1
36.4
12
9. 1
1.
46.2
3.8
NA
0
4.5
26.9
$46+2$
0
1
3.8 
DAPTIST MOSPITAL

OFMIAMI

Nursing Administration

November 22, 1994

Linda Stacey Doylan

13235-2 S W 110 Terrace

Miami, Florida 33186

Dear.Ms, Boylan:

Your rescatel ptoposa "Perecptions of Coltaboration Between Emergency Nurses and Paramedics" has becr approved hy the fatien Caic Research Committec. The Cominitee requests fou address the following isstes:

- Obtain approval, before you begin yotr data collection, from the Emergency Deparment Administration; Craig McCan and Cluarles Sperrazza.

- Comparison of the nurses betveer the different luatimitions has not been approved.

- Restits of the sludy are to be provided to the Emergency Department and Patien Care Rescarch Conmittec upon complction of the siudy,

Good luck with yout research. If I call be of any further assistance, please let me know.

Sincerciy,

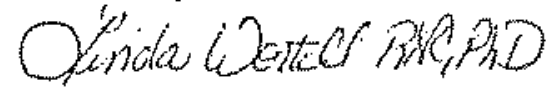

Linda Wortell, RNC, PhD

Chairperson Patient Care Rescarch Commines.

LW/II

(305) $5 \times 0-1960$ 
October 24, 1994

Ms Linda Boylan

Fiorida International. Iniversity

Miami, Elotida

Dear Ms. Eoylan:

Congratulations on your efforts to complete the reguirement: for a Masters of science in Nuising. We look forwat to assiating you in your research project.

Special Assistant Robir Duren will be the pamary liaison, and rust be contacted brior to any contact with our. paramedics. I am sure that you can undexstand that while wa will attempt to facilitate yout study we must primarily assure our commity of fire-rescue service.

I would also ask that you be so kind as to provide our Department with a copy of your findings as well as any ideas
which may erhance our public service.

If you need any further assistance please contact special Assistant Robin Duren at $253-3765$.

Sincerely,

E. C.
E. C. Nearsey
Assistant Chief

$\mathrm{ECN} / \mathrm{SCl}$

ce: Division 3 
Date: October 13,1994

Memo: Linda stacy Boylan Roif.

From: Gwen Young R.N., M.S.li. in

Chairperson, Nursing Research Comnittee

The Nursing Research Comit tee have reviewed your proposal and have granted permission for you to start data collection at south Mami Hospital at your convenience.

Enclosed is a copy of the procednre for conducting research at South Miami flospital. Please Eotward a copy of the completed study for our recouds, and feel free to contact us if we can be of further assistance.

co. Ms. L. Granata 
October 3t, 1994

Ms. Linda Boylan

South Miami Hospital

Charge Review Department

South Miani, FL

Dear Linda:

I an pleased to inform you that. Thave reviewed your research proposal titad "Perceptions of Collaboration between Emergency Nurses and Paramedics". T hava discussed the proposal with the Emergency Pepattment's Muse Manager and we both approve of the staff participating in your studi

please contact cindy Braswell, RN, BSN, Nurse Manager of the Emergency Department as needed to facilitate the surveys reaching

Best wishes in your endeavor.

sincerely,

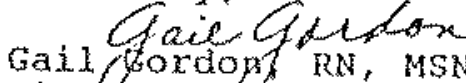

Vice Pxesident of Nursing

GG:DLt

co: Cindy Braswell, RN, BSK 
October 25, 1994

Ms Linda Boylan

Florida International University

Miami, Florida

Dear Ms. Boylan:

Congradulations on your efforts to complete the reauirements for a Masters of Science in narsing. We look foward to assisting you in your research project at Deering Hospital, Emergency Room.

Gloria McEleven, RN., Emergency Services Director will be the primary liason between Deering Hospital Emergency Room and the Principal Investigatom. we would also ask that you provide us with a copy of your sindings.

- If you need any further assistance, please contact Gloria McEleven at 256-5004.

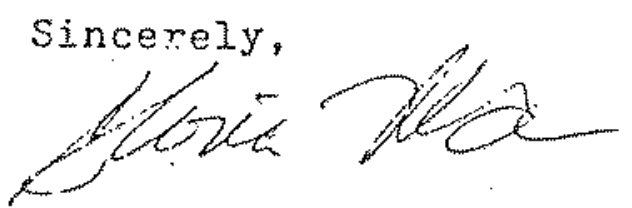

Gloria McEleven, PN

Emergency Services Director 